\title{
By Force of Habit: A Consumption-Based Explanation of Aggregate Stock Market Behavior
}

\section{Citation}

Campbell, John Y., and John H. Cochrane. 1999. By force of habit: a consumption-based

explanation of aggregate stock market behavior. Journal of Political Economy 107(2): 205-251.

\section{Published Version}

http://dx.doi.org/10.1086/250059

\section{Permanent link}

http://nrs.harvard.edu/urn-3:HUL.InstRepos:3119444

\section{Terms of Use}

This article was downloaded from Harvard University's DASH repository, and is made available under the terms and conditions applicable to Other Posted Material, as set forth at http:// nrs.harvard.edu/urn-3:HUL.InstRepos:dash.current.terms-of-use\#LAA

\section{Share Your Story}

The Harvard community has made this article openly available.

Please share how this access benefits you. Submit a story.

Accessibility 


\section{By Force of Habit: A Consumption-Based Explanation of Aggregate Stock Market Behavior}

\section{John Y. Campbell}

Harvard University and National Bureau of Economic Research

\section{John H. Cochrane}

University of Chicago, Federal Reserve Bank of Chicago, and National Bureau of Economic Research

We present a consumption-based model that explains a wide variety of dynamic asset pricing phenomena, including the procyclical variation of stock prices, the long-horizon predictability of excess stock returns, and the countercyclical variation of stock market volatility. The model captures much of the history of stock prices from consumption data. It explains the short- and long-run equity premium puzzles despite a low and constant risk-free rate. The results are essentially the same whether we model stocks as a claim to the consumption stream or as a claim to volatile dividends poorly correlated with consumption. The model is driven by an independently and identically distributed consumption growth process and adds a slow-moving external habit to the standard power utility function. These features generate slow countercyclical variation in risk premia. The model posits a fundamentally novel description of risk premia: Investors fear stocks primarily because they do poorly in recessions unrelated to the risks of long-run average consumption growth.

Carmpbell thanks the National Science Foundation for research support. Cochrane thanks the National Science Foundation and the Graduate School of Business of the University of Chicago for research support. We thank Andrew Abel, George Constantinides, John Heaton, Robert Lucas, Rajnish Mehra, and especially Lars Hansen for helpful comments. 


\section{Introduction}

A number of empirical observations suggest tantalizing links between asset markets and macroeconomics. Most important, equity risk premia seem to be higher at business cycle troughs than they are at peaks. Excess returns on common stocks over Treasury bills are forecastable, and many of the variables that predict excess returns are correlated with or predict business cycles (Ferson and Merrick 1987; Fama and French 1989). The literature on volatility tests mirrors this conclusion: price/dividend ratios move procyclically, but this movement cannot be explained by variation in expected dividends or interest rates, indicating large countercyclical variation in expected excess returns (Campbell and Shiller 1988a, 1988b; Shiller 1989; Cochrane 1991, 1992). Estimates of conditional variances of returns also change through time (see Bollerslev, Chou, and Kroner [1992] for a survey), but they do not move one for one with estimates of conditional mean returns. Hence the slope of the conditional mean-variance frontier, a measure of the price of risk, changes through time with a business cycle pattern (Harvey 1989; Chou, Engle, and Kane 1992).

As yet, there is no accepted economic explanation for these observations. In the language of finance, we lack a successful theory and measurement procedure for the fundamental sources of risk that drive expected returns. In the language of macroeconomics, standard business cycle models utterly fail to reproduce the level, variation, and cyclical comovement of equity premia.

We show that many of the puzzles in this area can be understood with a simple modification of the standard representative-agent consumption-based asset pricing model. The central ingredient is a slow-moving habit, or time-varying subsistence level, added to the basic power utility function. As consumption declines toward the habit in a business cycle trough, the curvature of the utility function rises, so risky asset prices fall and expected returns rise.

We model consumption growth as an independently and identically distributed (i.i.d.) lognormal process, with the same mean and standard deviation as postwar consumption growth. Our model can accommodate more complex consumption processes, including processes with predictability, conditional heteroskedasticity, and nonnormality. But these features are not salient characteristics of consumption data. More important, we want to emphasize that the model generates interesting asset price behavior internally, not from exogenous variation in the probability distribution of consumption growth. In this respect, our approach is the opposite of that of Kandel and Stambaugh $(1990,1991)$, who use fairly standard prefer- 
ences but derive some of these phenomena from movement over time in the conditional moments of consumption growth.

We choose our model's functional form and parameters so that the risk-free interest rate is constant. We do this for several reasons. First, there appears to be only limited variation in the real risk-free rate in historical U.S. data, and the variation that does exist is not closely related to the business cycle or to movements in stock prices. Second, we want to show how the model can explain stock market behavior entirely by variation in risk premia without any movement in the risk-free rate. Third, many habit persistence models with exogenous consumption give rise to wild variation in risk-free rates. When production is added, consumers smooth away the consumption fluctuations. (See Jermann [1998] for a quantitative example.) A constant risk-free rate is consistent with a linear production technology and therefore suggests that our results will be robust to the addition of an explicit production sector.

We generate artificial data from the model, and then we check whether the artificial data display the patterns found in the empirical literature. The model replicates the level of the risk-free rate, the mean excess stock return (the equity premium), and the standard deviation of excess stock returns. Most important, the model fits the dynamic behavior of stock prices. It matches the level and volatility of price/dividend ratios and the long-horizon forecastability of stock returns, and it produces persistent variation in return volatility. It replicates the finding of the volatility test literature that the volatility of stock price/dividend ratios or returns cannot be accounted for by changing expectations of future dividend growth rates. The model also accounts for much of the observed low correlation between stock returns and consumption growth. Despite a lognormal forcing process, the model predicts nonnormal, negatively skewed stock prices and returns, with occasional crashes that are larger than the booms. We feed the model actual consumption data, and we find that the price/dividend ratios and returns predicted by our model provide a surprisingly good account of fluctuations in stock prices and returns over the last century. All these interesting and seemingly unrelated phenomena are in fact reflections of the same phenomenon, which is at the core of the model: a slowly time-varying, countercyclical risk premium.

\section{A. Habit Formation}

Habit formation has a long history in the study of consumption. Deaton and Muellbauer (1980) survey early work in the area, and Deaton (1992) gives a more recent overview. Ryder and Heal (1973), 
Sundaresan (1989), and Constantinides (1990) are major theoretical papers on the subject. Habit formation captures a fundamental feature of psychology: repetition of a stimulus diminishes the perception of the stimulus and responses to it. Habit formation can explain why consumers' reported sense of well-being often seems more related to recent changes in consumption than to the absolute level of consumption. In macroeconomics, habit persistence can explain why recessions are so feared even though their effects on output are small relative to a few years' growth.

Our habit specification has three distinctive features. First, we specify that habit formation is external, as in Abel's (1990) "catching up with the Joneses" formulation or Duesenberry's (1949) "relative income" model. An individual's habit level depends on the history of aggregate consumption rather than on the individual's own past consumption. This specification simplifies our analysis. It eliminates terms in marginal utility by which extra consumption today raises habits tomorrow, while retaining fully rational expectations.

Second, we specify that habit moves slowly in response to consumption, in contrast to empirical specifications in which each period's habit is proportional to the last period's consumption (e.g., Ferson and Constantinides 1991). This feature produces slow mean reversion in the price/dividend ratio, long-horizon return forecastability, and persistent movements in volatility.

Third, we specify that habit adapts nonlinearly to the history of consumption. The nonlinearity keeps habit always below consumption and keeps marginal utility always finite and positive even in an endowment economy. In many models, including those of Sundaresan (1989), Ferson and Constantinides (1991), Heaton (1995), and Chapman (1998), consumption can fall below habit with undesirable consequences. Abel $(1990,1999)$ keeps marginal utility positive by changing utility from $u(C-X)$ to $u(C / X)$, but this specification eliminates changing risk aversion. Most important, the nonlinear habit specification is essential for us to capture time variation in the Sharpe ratio (mean to standard deviation of returns) and a constant risk-free rate.

\section{The Model}

\section{A. Preferences and Technology}

Identical agents maximize the utility function

$$
E \sum_{t=0}^{\infty} \delta^{\prime} \frac{\left(C_{t}-X_{t}\right)^{1-\gamma}-1}{1-\gamma}
$$


Here $X_{t}$ is the level of habit, and $\delta$ is the subjective time discount factor.

It is convenient to capture the relation between consumption and habit by the surplus consumption ratio $S_{t} \equiv\left(C_{t}-X_{t}\right) / C_{t}$. The surplus consumption ratio increases with consumption: $S_{t}=0$ corresponds to an extremely bad state in which consumption is equal to habit; $S_{t}$ approaches one as consumption rises relative to habit. The local curvature of the utility function, which we write as $\eta_{l}$, is related to the surplus consumption ratio by

$$
\eta_{t} \equiv-\frac{C_{t} u_{c t}\left(C_{t}, X_{t}\right)}{u_{c}\left(C_{t}, X_{t}\right)}=\frac{\gamma}{S_{t}}
$$

Thus low consumption relative to habit, or a low surplus consumption ratio, implies a high local curvature of the utility function.

To complete the description of preferences, we must specify how the habit $X_{t}$ responds to consumption. Through most of our analysis we use an external habit specification in which habit is determined by the history of aggregate consumption rather than the history of individual consumption. Define

$$
S_{\imath}^{a} \equiv \frac{C_{\imath}^{a}-X_{t}}{C_{\imath}^{a}}
$$

where $C^{a}$ denotes average consumption by all individuals in the economy. We specify how each individual's habit $X_{l}$ responds to the history of aggregate consumption $C^{a}$ by specifying a process for $S_{\imath}^{a}$. The log surplus consumption ratio $s_{\imath}^{a} \equiv \ln S_{\imath}^{a}$ evolves as a heteroskedastic $\operatorname{AR}(1)$ process,

$$
s_{t+1}^{a}=(1-\phi) \bar{s}+\phi s_{t}^{a}+\lambda\left(s_{t}^{a}\right)\left(c_{t+1}^{a}-c_{i}^{a}-g\right),
$$

where $\phi, g$, and $\bar{s}$ are parameters. (Throughout, we use lowercase letters to indicate logs.) We call $\lambda\left(s_{t}^{a}\right)$ the sensitivity function, and we specify it further below. Substituting (2) into (3), we see that (3) does in fact describe how habit $X_{t}$ adjusts to the history of consumption $\left\{C_{t-j}^{a}\right\}$. Though this adjustment is nonlinear, to a first approximation near the steady state $\bar{s}$, equation (3) implies that habit $x_{t}$ itself adjusts slowly and geometrically to consumption $c_{t}^{a}$ with coefficient $\phi$. In equilibrium, identical individuals choose the same level of consumption, so $C_{t}=C_{\imath}^{a}$ and $S_{t}=S_{\imath}^{a}$. Therefore, we drop the $a$ superscripts in what follows where they are not essential for clarity.

Having described tastes, we now turn to technology. We model consumption growth as an i.i.d. lognormal process

$$
\Delta c_{t+1}=g+v_{t+1}, \quad v_{t+1} \sim \text { i.i.d. } \mathcal{N}\left(0, \sigma^{2}\right) .
$$


It is convenient, though not essential, to use the same value $g$ for the mean consumption growth rate and the parameter $g$ in the habit accumulation equation (3).

We can regard equation (4) as the specification of the endowment process and close our model as an endowment economy. In principle, this interpretation does not imply a loss of generality: If the statistical model of the "endowment" is the same as the equilibrium consumption process from a production economy, then the joint asset price-consumption process is the same whether the economy is truly an endowment or a production economy. In practice, the asset pricing predictions of many habit persistence economies are strongly affected by the specification of technology. In many endowment economies with habits and random walk consumption, riskfree rates vary a great deal, as the varying surplus consumption ratio gives rise to strong motives for intertemporal substitution. When production is added to these economies, consumers make strong use of production opportunities to smooth marginal utility over time. The interest rate variation is quieted down, but the equilibrium consumption process moves far from a random walk (Jermann 1998). However, we shall pick the functional forms and parameters of our model to generate a constant real risk-free rate. Therefore, we can also close the model with a linear technology:

$$
\begin{aligned}
K_{t+1} & =R^{f}\left(K_{t}+E_{t}-C_{t}\right), \\
\Delta e_{t+1} & =g+v_{t+1}, \quad v_{t+1} \sim \text { i.i.d. } \mathcal{N}\left(0, \sigma^{2}\right),
\end{aligned}
$$

where $K_{t}$ and $E_{t}$ denote the capital stock and an exogenous endowment or additive technology shock, respectively. This specification results in exactly the same process for consumption and asset prices as the endowment specification does. This fact suggests that the model's consumption and asset pricing implications will not be much affected if the model is closed with any standard concave specification of technology that gives easy opportunities for intertemporal transformation and thus a roughly constant risk-free interest rate.

\section{B. Marginal Utility}

Since habit is external, marginal utility is

$$
u_{c}\left(C_{t}, X_{t}\right)=\left(C_{t}-X_{t}\right)^{-\gamma}=S_{t}^{-\gamma} C_{t}^{-\gamma} \text {. }
$$

The intertemporal marginal rate of substitution is then

$$
M_{t+1} \equiv \delta \frac{u_{t}\left(C_{t+1}, X_{t+1}\right)}{u_{c}\left(C_{t}, X_{t}\right)}=\delta\left(\frac{S_{t+1}}{S_{t}} \frac{C_{t+1}}{C_{t}}\right)^{-\gamma}
$$


It is related to the state variable $s_{t}$ and the log consumption innovation $v_{t+1}$ by

$$
M_{t+1}=\delta G^{-\gamma} e^{-\gamma\left(s_{t+1}-s_{t}+v_{t+1}\right)}=\delta G^{-\gamma} e^{-\gamma\left((\phi-1)\left(s_{t}-\delta\right)+\left[1+\lambda\left(s_{s}\right)\right] v_{t+1}\right)} .
$$

We can now calculate moments of the marginal rate of substitution and find asset prices.

Slope of the Mean-Standard Deviation Frontier

The slope of the conditional mean-standard deviation frontier can be found from the conditional moments of the marginal rate of substitution. Following Shiller (1982), Hansen and Jagannathan (1991) show that the first-order condition $0=E_{t}\left(M_{t+1} R_{t+1}^{i}\right)$ for an excess return $R^{e}$ implies that the Sharpe ratio of any asset return must obey

$$
\frac{E_{t}\left(R_{t+1}^{e}\right)}{\sigma_{t}\left(R_{i+1}^{e}\right)}=-\rho_{t}\left(M_{t+1}, R_{t+1}^{e}\right) \frac{\sigma_{t}\left(M_{t+1}\right)}{E_{t}\left(M_{t+1}\right)} \leq \frac{\sigma_{t}\left(M_{t+1}\right)}{E_{t}\left(M_{t+1}\right)},
$$

where $\rho_{t}$ denotes a conditional correlation. In our model, $M$ is conditionally lognormal, ${ }^{1}$ so we can find the largest possible Sharpe ratio by

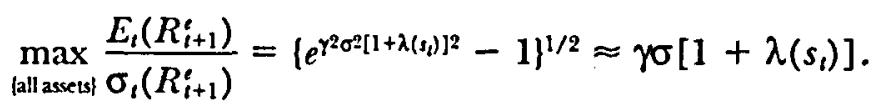

This formula helps us to specify the model. To produce a timevarying Sharpe ratio, $\lambda(s)$ must vary with $s$. To produce risk prices that are higher in bad times, when $s$ is low, $\lambda(s)$ and hence the volatility of $s$ must increase as $s$ declines.

\section{Risk-Free Interest Rate}

The real risk-free interest rate is the reciprocal of the conditionally expected stochastic discount factor

$$
R_{t}^{\prime}=\frac{1}{E_{t}\left(M_{t+1}\right)}
$$

' For lognormal $M$ with mean $\mu$ and standard deviation $\sigma$,

$$
\frac{\sigma(M)}{E(M)}=\frac{\sqrt{E\left(M^{2}\right)-E(M)^{2}}}{E(M)}=\frac{\sqrt{e^{2 \mu+2 \sigma^{2}}-e^{2 \mu+\sigma^{2}}}}{e^{\mu+\left(\sigma^{2} / 2\right)}}=\sqrt{e^{\sigma^{2}}-1} .
$$


From equation (5) and the lognormality of consumption growth, the $\log$ risk-free rate is

$$
r_{t}^{f}=-\ln (\delta)+\gamma g-\gamma(1-\phi)\left(s_{t}-\bar{s}\right)-\frac{\gamma^{2} \sigma^{2}}{2}\left[1+\lambda\left(s_{t}\right)\right]^{2} .
$$

The $s_{t}-\bar{s}$ term reflects intertemporal substitution. If the surplus consumption ratio is low, the marginal utility of consumption is high. If there were no shocks to consumption, marginal utility would fall as the surplus consumption ratio reverts to $\bar{s}$. The consumer would then like to borrow, which would drive up the equilibrium risk-free interest rate. We can interpret the last term in equation (8) as a precautionary savings term. As uncertainty increases, consumers are more willing to save, and this willingness drives down the equilibrium risk-free interest rate.

In the data, we notice relatively little variation in risk-free rates. This means that the serial correlation parameter $\phi$ must be near one, or $\lambda\left(s_{t}\right)$ must decline with $s_{t}$ so that uncertainty is high when $s$ is low and the precautionary saving term offsets the intertemporal substitution term. The decline of $\lambda\left(s_{t}\right)$ with $s_{t}$ is the same condition we need to get countercyclical variation in the price of risk. We now use this insight to pick the functional form of $\lambda\left(s_{t}\right)$.

\section{Choosing the Sensitivity Function $\lambda\left(\mathrm{s}_{\mathrm{t}}\right)$}

We have not yet specified the functional form of $\lambda\left(s_{i}\right)$. We choose $\lambda\left(s_{t}\right)$ to satisfy three conditions: (1) The risk-free interest rate is constant; (2) habit is predetermined at the steady state $s_{t}=\bar{s}$; and (3) habit is predetermined near the steady state or, equivalently, habit moves nonnegatively with consumption everywhere.

We have already discussed the motivation for a constant risk-free interest rate. We further restrict habit behavior to keep the specification close to traditional and sensible notions of habit. We normally think that it takes time for others' consumption to affect one's habits. In our model, habit cannot be completely predetermined, or a sufficiently low realization of consumption growth would leave consumption below habit, in which case a power utility function is undefined. Hence, we require that habit be predetermined, but only at and near the steady state. Finally, the notion of habit would be strained if we allowed habit to move in the opposite direction from consumption.

These three considerations lead us to a restriction that must hold between the steady-state surplus consumption ratio $\bar{S}$ and the other parameters of the model, namely, 


$$
\bar{S}=\sigma \sqrt{\frac{\gamma}{1-\phi}},
$$

and they lead us to a specification of the sensitivity function

$$
\lambda\left(s_{t}\right)= \begin{cases}\frac{1}{\bar{S}} \sqrt{1-2\left(s_{t}-\bar{s}\right)}-1, & s_{t} \leq s_{\max } \\ 0 & s_{t} \geq s_{\max },\end{cases}
$$

where $s_{\max }$ is the value of $s_{t}$ at which the upper expression in (10) runs into zero:

$$
s_{\max } \equiv \bar{s}+\frac{1}{2}\left(1-\bar{S}^{2}\right) .
$$

In the continuous-time limit, the $s_{t}$ process never attains the region $s>s_{\max }$.

This specification achieves the three objectives set out above. First, simply plugging the definition of $\bar{S}$, (9), and the definition of $\lambda\left(s_{t}\right)$, (10), into the formula for the risk-free rate, (8), we see that the riskfree rate is a constant:

$$
r_{t}^{f}=-\ln (\delta)+\gamma g-\left(\frac{\gamma}{\bar{S}}\right)^{2} \frac{\sigma^{2}}{2}=-\ln (\delta)+\gamma g-\frac{\gamma}{2}(1-\phi) .
$$

Second, differentiating the transition equation (3), we obtain

$$
\frac{d x_{t+1}}{d c_{t+1}}=1-\frac{\lambda\left(s_{t}\right)}{e^{-s_{t+1}}-1} \approx 1-\frac{\lambda\left(s_{t}\right)}{e^{-s_{t}}-1} .
$$

The latter approximation holds near the steady state. To obtain $d x / d c=0$ at $s_{t}=\bar{s}$, we require

$$
\lambda(\bar{s})=\frac{1}{\bar{S}}-1
$$

When equation (10) is evaluated at $\bar{s}$, it satisfies this condition. Third, to ensure that habit is predetermined in a neighborhood of the steady state, we add the requirement

$$
\left.\frac{d}{d s}\left(\frac{d x}{d c}\right)\right|_{s=3}=0
$$

This condition also implies that habit moves nonnegatively with consumption everywhere since $d x / d c$ is a $U$-shaped function of $s$. Taking 
the derivative $(d / d s)(d x / d c)$ of the expression in (13) and setting it to zero at $s=\bar{s}$, we obtain

$$
\lambda^{\prime}(\bar{s})=-\frac{1}{\bar{s}}
$$

Equation (10) satisfies this condition. Since the functional form of $\lambda\left(s_{t}\right)$ was already determined by the first two conditions, this condition determines the constraint (9) on the parameters of the model.

Panel $a$ of figure 1 plots the sensitivity function $\lambda\left(s_{t}\right)$ against the surplus consumption ratio, given the parameter values described below. The sensitivity function $\lambda\left(s_{t}\right)$ is a shifted square root function of $-s_{t}$, so $\lambda$ increases to infinity as $s_{t}$ declines to minus infinity, or as $S_{t}=e^{s_{t}}$ declines to zero in the figure. As we discussed above, a negative relationship between $\lambda\left(s_{t}\right)$ and $s_{t}$ is needed to produce a constant risk-free interest rate and a countercyclical price of risk. Where $\lambda\left(s_{t}\right)$ hits zero, we see the upper bound of the surplus consumption ratio, $S_{\max }$.

Panel $b$ of figure 1 plots the derivative of log habit with respect to $\log$ consumption, as given by equation (13). The figure verifies that habit does not move contemporaneously with consumption$d x / d c=0$-at and near the steady state, marked by a vertical line, and that habit responds positively to consumption- $d x / d c \geq 0-$ everywhere. As the surplus consumption ratio declines to zero or increases to its upper bound (the vertical dashed line), log habit starts to move one for one with log consumption in order to keep habit below consumption or the surplus consumption ratio below its upper bound.

\section{Time Variation in the Riskless Interest Rate}

Different functional forms for $\lambda\left(s_{t}\right)$ can of course generate riskless interest rates that vary with the state variable. For example, a natural generalization is to choose $\lambda\left(s_{t}\right)$ so that the interest rate is a linear function of the state $s_{t}$, rather than a constant:

$$
r_{t}^{f}=r_{0}^{f}-B\left(s_{t}-\bar{s}\right) \text {. }
$$

The only difference this modification makes to the previous analysis is that the relation between parameters in equation (9) generalizes to

$$
\bar{S}=\sigma \sqrt{\frac{\gamma}{1-\phi-(B / \gamma)}} .
$$

This generalization of the model produces a rich term structure of interest rates. Since the risk-free rate is a linear function of the state 
$\mathbf{a}$

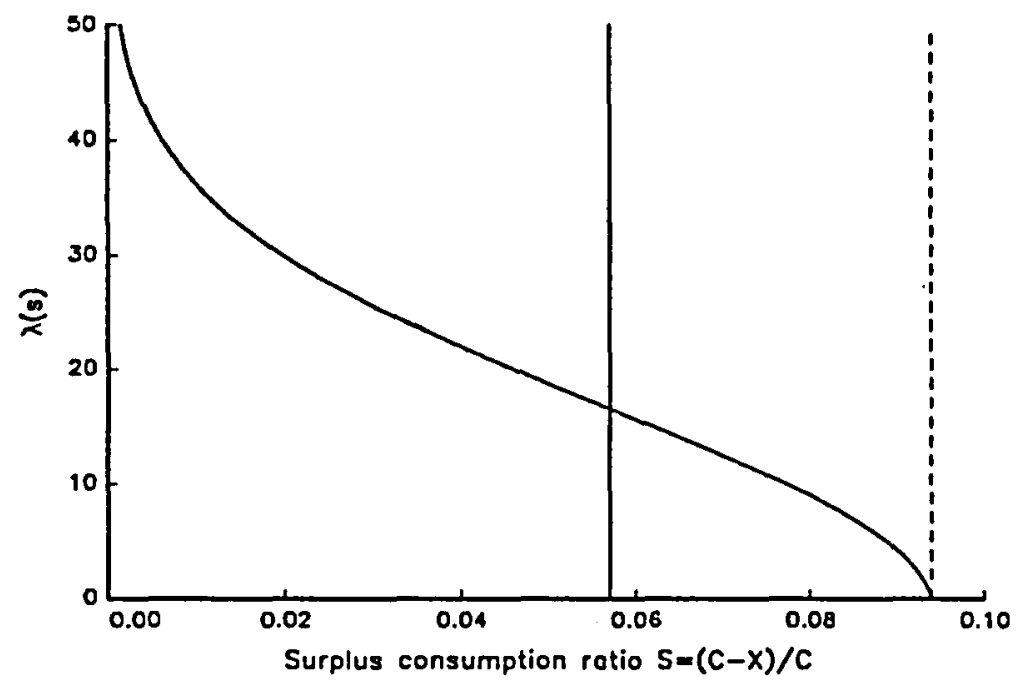

b

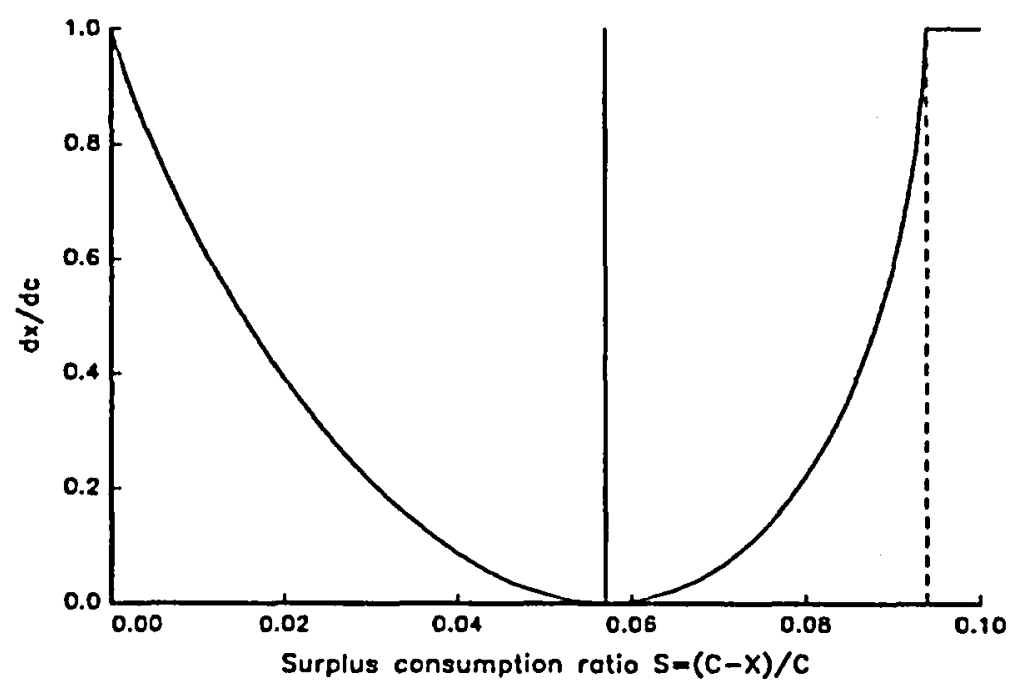

FIc. 1.- $a$, Sensitivity function $\lambda\left(s_{t}\right), b$, Implied sensitivity of habit $x$ to contemporaneous consumption. The vertical solid line in this and subsequent figures shows the steady-state surplus consumption ratio $\bar{S}$. The dashed vertical line shows the maximum surplus consumption ratio $S_{\max }$. 
variable $s_{t}$ and since from equation (10) the conditional standard deviation of $s_{t}$ is very close to a square root function of $s_{t}$, this generalized model is similar to square root models of the term structure such as the model of Cox, Ingersoll, and Ross (1985). The generalized model also implies that yield spreads are functions of the state variable $s_{t}$, so they forecast stock and bond returns about as well as the dividend/price ratio. However, adding interest rate variation in this way has very little effect on the stock market results on which we focus below. The working paper version of this article (Campbell and Cochrane 1995) includes explicit calculations of the term structure and its forecasts of stock and bond returns.

\section{Prices of Long-Lived Assets}

Pricing a Consumption Claim

We start by modeling stocks as a claim to the consumption stream. This is the simplest specification; it is common in the equity premium literature, allowing an easy comparison of results; and it is the natural definition of the "market" or "wealth portfolio" studied in finance theory. From the basic pricing relation and the definition of returns,

$$
1=E_{t}\left[M_{t+1} R_{t+1}\right], \quad R_{t+1} \equiv \frac{P_{t+1}+D_{t+1}}{P_{t}},
$$

the price/dividend or, equivalently, the price/consumption ratio for a consumption claim satisfies

$$
\frac{P_{t}}{C_{t}}\left(s_{t}\right)=E_{t}\left[M_{t+1} \frac{C_{t+1}}{C_{t}}\left[1+\frac{P_{t+1}}{C_{t+1}}\left(s_{t+1}\right)\right]\right] .
$$

The surplus consumption ratio $s_{l}$ is the only state variable for the economy, so the price/consumption ratio is a function only of $s_{t}$. We substitute for $M_{t+1}$ from (5) and consumption growth from (4) and then solve this functional equation numerically on a grid for the state variable $s_{t}$, using numerical integration over the normally distributed shock $v_{t+1}$ to evaluate the conditional expectation. Given the price/consumption ratio as a function of state, we calculate expected returns, the conditional standard deviation of returns, and other interesting quantities.

\section{Imperfectly Correlated Dividends} and Consumption

The growth rates of stock market dividends and consumption are only weakly correlated in U.S. data. This fact suggests that it may be 
important to model dividends and consumption separately rather than to treat them as a single process. We separate dividends and consumption in a particularly simple way in order to avoid adding state variables to our model. Surprisingly, we find that prices and returns of dividend claims behave very much like those of consumption claims, despite the low correlation between consumption and dividend growth rates.

We specify an i.i.d. process for dividend growth, imperfectly correlated with consumption growth. Letting $D$ denote the level of dividends and $d$ the log of dividends, we specify

$$
\Delta d_{t+1}=g+w_{t+1} ; \quad w_{t+1} \sim \text { i.i.d. } \mathcal{N}\left(0, \sigma_{w}^{2}\right), \operatorname{corr}\left(w_{t}, v_{t}\right)=\rho .
$$

The price/dividend ratio of a claim to the dividend stream then satisfies

$$
\frac{P_{t}}{D_{t}}\left(s_{t}\right)=E_{t}\left[M_{t+1} \frac{D_{t+1}}{D_{t}}\left[1+\frac{P_{t+1}}{D_{t+1}}\left(s_{t+1}\right)\right]\right] \text {. }
$$

We calculate this price/dividend ratio as a function of state in much the same manner as the price/consumption ratio of the consumption claim. Our appendix (Campbell and Cochrane [1998a], available from the authors) gives details of the calculation.

The correlation between consumption growth and dividend growth in the model (18) is the same at all horizons, and dividends wander arbitrarily far from consumption as time passes. It would be better to make dividends and consumption cointegrated. We have explored a model in which the log dividend/consumption ratio is i.i.d. and the correlation of one-period dividend and consumption growth rates is low as in the data. This model behaves so similarly to the basic consumption claim model that graphs of the solutions are indistinguishable. A cointegrated model with a persistent log dividend/consumption ratio would be more realistic, but this modification would require an additional state variable. Any such model is likely to make the consumption and dividend claims even more alike than in our specification (18) since it increases the correlation between dividends and consumption at long horizons.

\section{E. Choosing Parameters}

We compare the model to two data sets: (1) postwar (1947-95) value-weighted New York Stock Exchange stock index returns from the Center for Research in Security Prices (CRSP), 3-month Treasury bill rate, and per capita nondurables and services consumption and (2) a century-long annual data set of Standard \& Poors 500 
TABLE 1

Parameter Choices

\begin{tabular}{lcc}
\hline \hline Parameter & Variable & Value \\
\hline Assumed: & & \\
Mean consumption growth $(\%)^{*}$ & $g$ & 1.89 \\
Standard deviation of consumption growth $(\%)^{*}$ & $\sigma$ & 1.50 \\
Log risk-free rate (\%)* & $\gamma^{\prime}$ & .94 \\
Persistence coefficient* & $\phi$ & .87 \\
Utility curvature & $\gamma$ & 2.00 \\
Standard deviation of dividend growth (\%)* & $\sigma_{\omega}$ & 11.2 \\
Correlation between $\Delta d$ and $\Delta c$ & $\rho$ & .2 \\
Implied: & $\delta$ & .89 \\
Subjective discount factor* & $\delta$ & .057 \\
Steady-state surplus consumption ratio & $S$ & .094 \\
Maximum surplus consumption ratio & $S_{\max }$ & \\
\hline
\end{tabular}

* Annualized values, e.g., $12 \mathrm{~g}, \sqrt{12} \sigma, 12 r^{\prime}, \phi^{12}$, and $\delta^{12}$, since the model is simulated at a monthly frequency.

stock and commercial paper returns (1871-1993) and per capita consumption (1889-1992) from Campbell (1999).

We choose the free parameters of the model to match certain moments of the postwar data. Table 1 summarizes our parameter choices. We take the mean and standard deviation of log consumption growth, $g$ and $\sigma$, to match the consumption data. We choose the serial correlation parameter $\phi$ to match the serial correlation of log price/dividend ratios. We choose the subjective discount factor $\delta$ to match the risk-free rate with the average real return on Treasury bills. Since the ratio of unconditional mean to unconditional standard deviation of excess returns is the heart of the equity premium puzzle, we search for a value of $\gamma$ so that the returns on the consumption claim match this ratio in the data.

We take the standard deviation of dividend growth, $\sigma_{w}$, from the CRSP data as well. Assigning a value $\rho$ for the correlation between dividend growth and consumption growth is a little trickier. If dividend growth were uncorrelated with consumption growth, a claim to dividend growth would have no risk premium. However, correlations are difficult to measure because they are sensitive to small changes in timing or time aggregation. Campbell (1999) reports correlations in postwar U.S. data varying from .05 to almost .25 as the measurement interval increases from 1 to 16 quarters and correlations in long-run annual U.S. data varying from almost .2 to just over .1 as the measurement interval increases from 1 to 8 years. In the very long run, one expects the correlation to approach 1.0 since dividends and consumption should share the same long-run trends. Furthermore, these point estimates are subject to large sampling 
error. The usual standard error formula $1 / \sqrt{T}$ for a correlation coefficient is .1 in a century and .15 in postwar data, so we cannot convincingly reject zero or accurately measure economically interesting correlations of .2 or .3. Given these results, we do not try to match a particular correlation but choose a baseline correlation of .2 to show that the model works well even with quite a low correlation between consumption and dividends. The results are insensitive to the precise value of this correlation.

\section{Solution and Evaluation}

In this section we solve the model numerically and characterize its behavior. Then we simulate data by drawing shocks from a random number generator, and we show how the simulated data replicate many interesting statistics found in actual data. Finally, we feed the model historical consumption shocks to see what it tells us about historical movements in stock prices.

\section{A. Asset Prices and the Surplus Consumption Ratio}

Stationary Distribution of the Surplus

Consumption Ratio

Figure 2 presents the stationary distribution of the surplus consumption ratio. The figure plots the distribution of the continuous-time

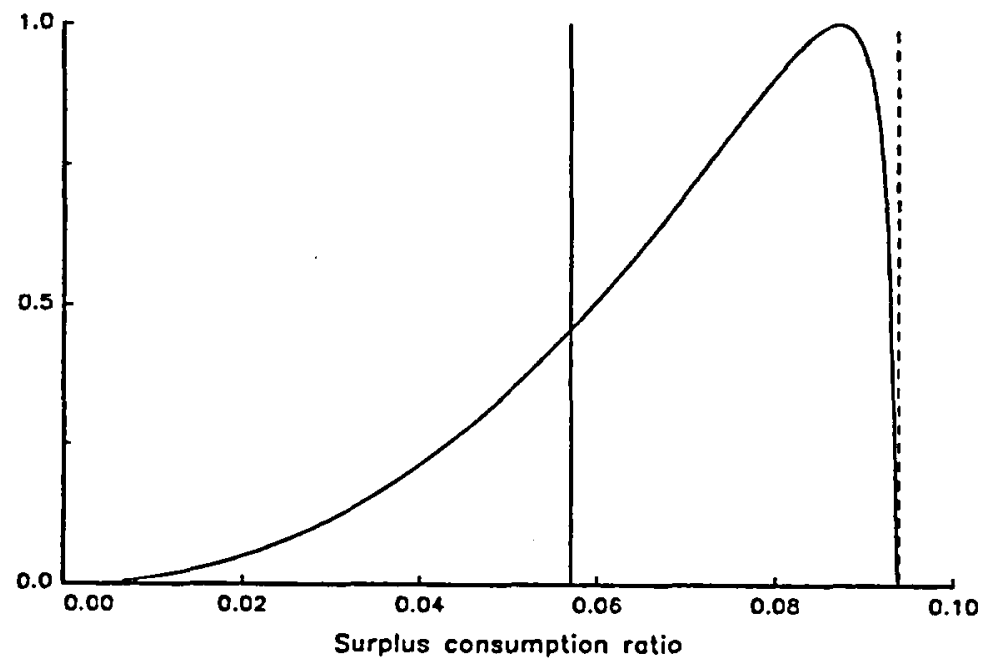

Fic. 2.-Unconditional distribution of the surplus consumption ratio. The solid vertical line indicates the steady-state surplus consumption ratio $\bar{S}$, and the dashed vertical line indicates the upper bound of the surplus consumption ratio $S_{\max }$. 
version of the process, calculated in the appendix (Campbell and Cochrane 1998a). This distribution is an excellent approximation to histograms of the discrete-time process for simulation time intervals of a year or less. With this stationary distribution and the slow mean reversion of the state variable in mind, one can get a good idea of the behavior of other quantities plotted against the state variable $S_{t}$.

The plot verifies that the unconditional distribution is well behaved: it does not pile up at the boundaries or wash out. The distribution of the surplus consumption ratio is negatively skewed. The surplus consumption ratio spends most of its time above the steadystate value $\bar{S}$, but there is an important fat tail of low surplus consumption ratios. We shall refer to a low surplus consumption ratio as a "recession" and a high surplus consumption ratio as a "boom." Thus the model predicts occasional deep recessions not matched by large booms.

Price/Dividend Ratios and the Surplus

Consumption Ratio

Figure 3 presents the price/dividend ratios of the consumption claim and the dividend claim as functions of the surplus consumption ratio. These are the central quantities for our simulations; all other variables are calculated from the price/dividend ratio.

The price/dividend ratios increase with the surplus consumption

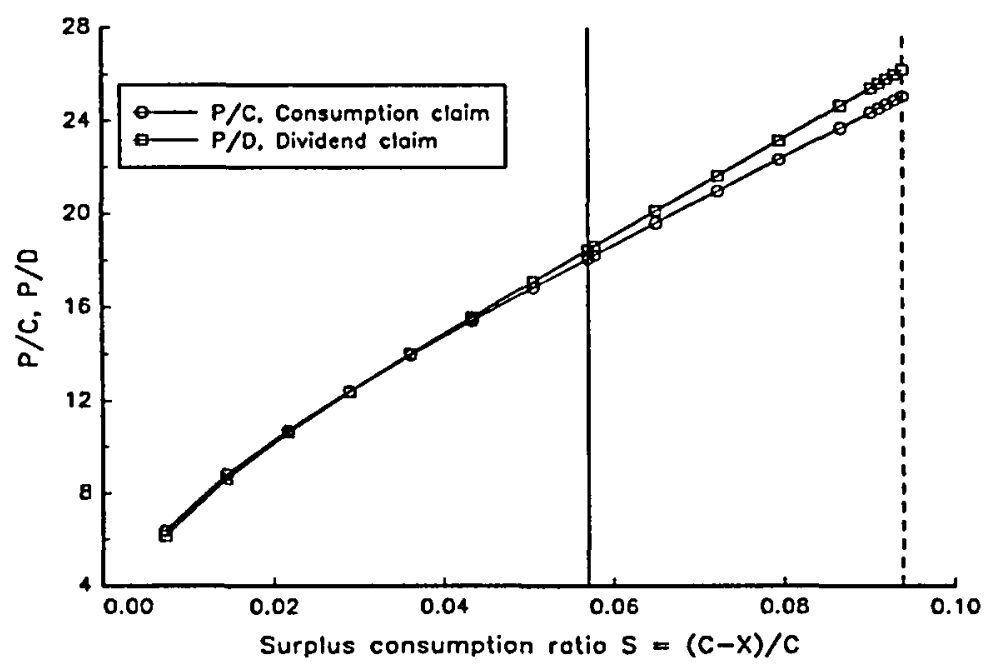

Fic. 3.-Price/dividend ratios as functions of the surplus consumption ratio 
ratio. When consumption is low relative to habit in a recession, the curvature of the utility function is high, and prices are depressed relative to dividends. Since the price/dividend ratios are nearly linear functions of the surplus consumption ratio and the distribution of the surplus consumption ratio is negatively skewed, the distribution of price/dividend ratios inherits this negative skewness despite i.i.d. lognormal consumption growth.

The price/dividend ratio of the dividend claim is almost exactly the same as the price/dividend ratio of the consumption claim despite the very low (.2) correlation of dividend growth with consumption growth. Dividend growth is much more volatile than consumption growth, so the regression coefficient $\beta=\rho \sigma_{\Delta d} / \sigma_{\Delta c}$ of dividend growth on consumption growth is roughly one. The systematic or priced components of the two assets are similar, and therefore so are their prices.

\section{Conditional Moments of Returns}

Figure 4 presents the expected consumption claim and dividend claim returns and the risk-free interest rate as functions of the surplus consumption ratio. As consumption declines toward habit, expected returns rise dramatically over the constant risk-free rate.

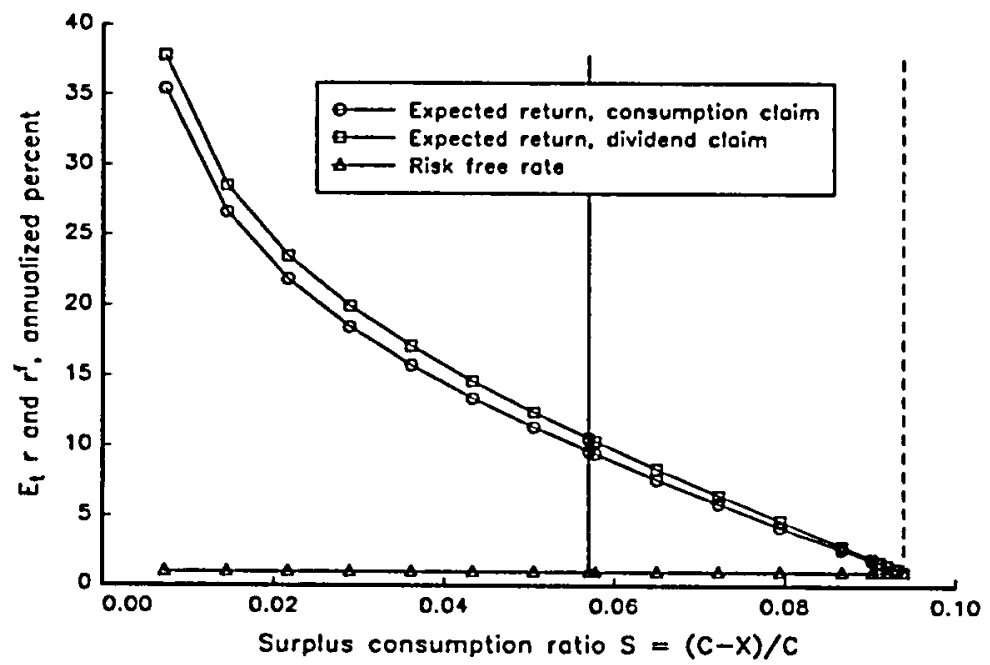

Fic. 4.-Expected returns and risk-free rate as functions of the surplus consumption ratio. 


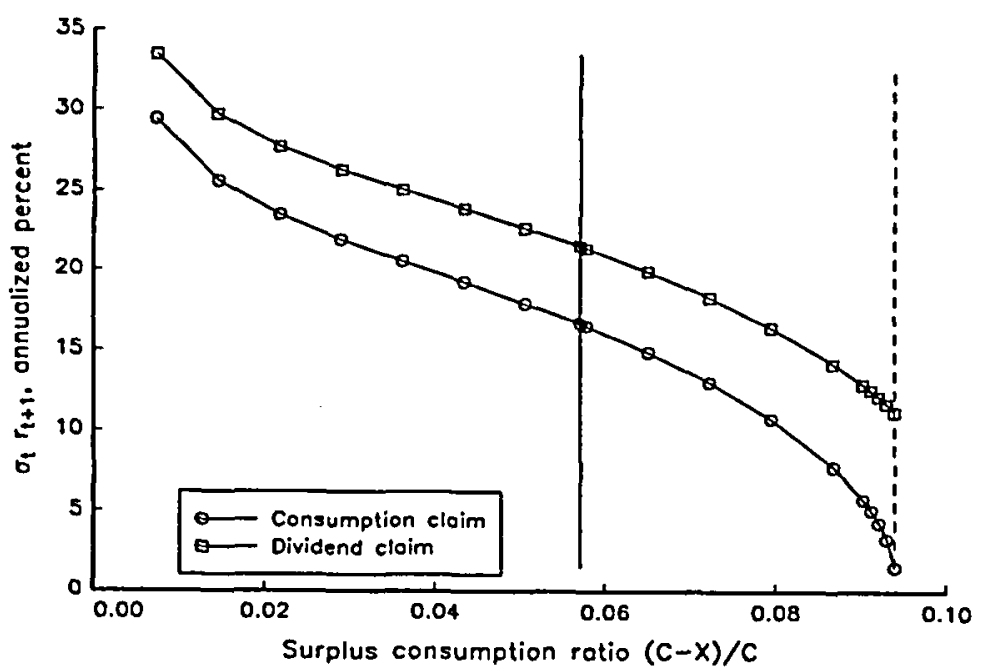

Fic. 5.-Conditional standard deviations of returns as functions of the surplus consumption ratio.

Figure 5 presents the conditional standard deviations of returns as functions of the surplus consumption ratio. As consumption declines toward habit, the conditional variance of returns increases. Thus the model produces several effects that have been emphasized in the autoregressive conditional heteroscedasticity (ARCH) literature: highly autocorrelated conditional variance in stock returns, a "leverage effect" that price declines increase volatility, and countercyclical variation in volatility.

In figure 4 , the expected return of the dividend claim is almost exactly the same as that of the consumption claim. In figure 5 the dividend claim has a noticeably higher standard deviation than the consumption claim but the same dependence on the surplus consumption ratio. The return on the dividend claim is

$$
R_{t+1}=\frac{P_{t+1}+D_{t+1}}{P_{t}}=\frac{\left(P_{t+1} / D_{t+1}\right)+1}{P_{t} / D_{t}} \times \frac{D_{t+1}}{D_{t}} \text {. }
$$

The expected returns are nearly identical because the price/dividend ratio and price/consumption ratio are nearly identical functions of state, and dividend and consumption growth are not predictable. The conditional standard deviation of the dividend claim inherits the same dependence on state through the nearly identical $P / D$ term but adds the extra, constant, standard deviation of dividend growth. 


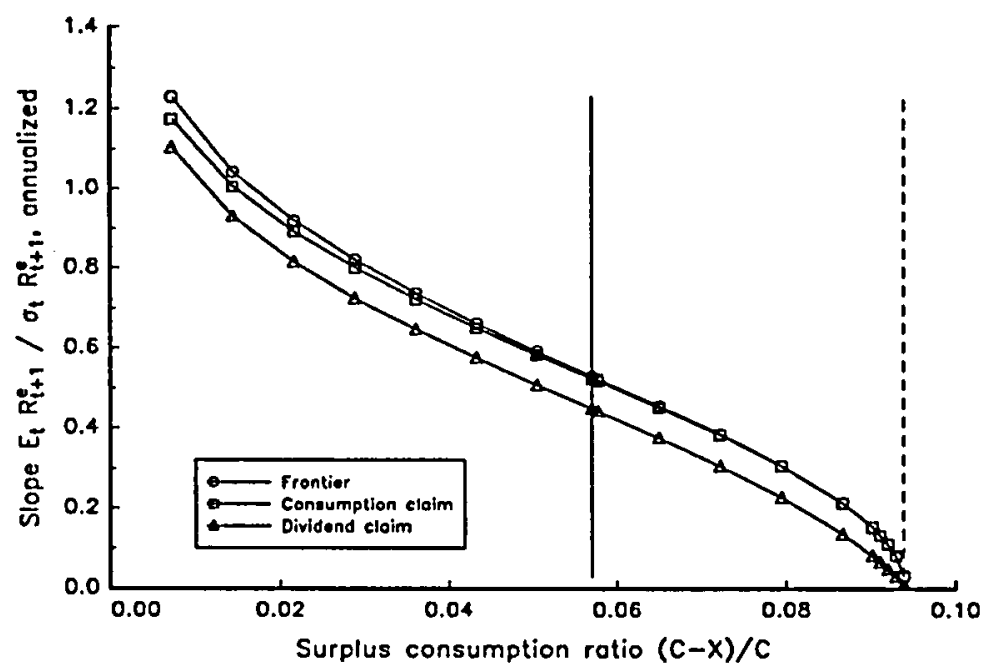

Fic. 6.-Sharpe ratios as functions of the surplus consumption ratio

\section{Conditional Sharpe Ratios}

Comparing figures 4 and 5, we see that conditional means and conditional standard deviations are different functions of the surplus consumption ratio, so the Sharpe ratio of conditional mean to conditional standard deviation of excess returns varies over time. To get a precise measure, figure 6 presents the Sharpe ratio as a function of the surplus consumption ratio. The top line is the maximum possible Sharpe ratio, calculated from the Hansen-Jagannathan bound, equation (7).

The consumption claim nearly attains the Sharpe ratio bound, implying that it is nearly conditionally mean-variance efficient. The consumption claim model has only one shock. Hence the only reason the consumption claim (or any claim whose return depends on the single shock) is not exactly conditionally mean-variance efficient is that it is nonlinearly related to the shock. For the consumption claim, the effects of such nonlinearity are slight.

The dividend claim has a slightly higher mean return and a substantially higher standard deviation since there is a second dividend growth shock as well as the consumption (discount rate) shock. Hence, the dividend claim has a somewhat lower Sharpe ratio and is less conditionally efficient. However, since the dividend payoff is correlated only .2 with the consumption claim payoff, it is surprising how close the Sharpe ratios are. In equation (20), most of the variation in the dividend claim return is due to changing risk premia and 
hence changing price/dividend ratios common to both assets, not to the volatility of the payoff itself.

The Sharpe ratios of both securities increase substantially when the surplus consumption ratio declines. In our model, recessions are times of low consumption relative to habit, low prices, somewhat higher standard deviations of returns, very much higher expected returns, and correspondingly high Sharpe ratios.

The top line of figure 6 is also interesting as a characterization of the discount factor. The conditional mean of the discount factor is constant, so this line plots the conditional standard deviation of the discount factor. That conditional standard deviation moves with the state variable $s_{t}$ and so inherits its positive serial correlation. Thus our economic model generates a time-series model for the second moment of the stochastic discount factor, like an ARCH model rather than an autoregressive moving average model. The HansenJagannathan analysis shows that this form is necessary in order to generate a time-varying risk premium.

\section{B. Statistics from Simulated Data}

We simulate 500,000 months of artificial data to calculate population values for a variety of statistics. In order to facilitate a comparison with historical data, we simulate the model at a monthly frequency and then construct time-averaged artificial annual data. As in the actual data, we average the level of consumption in each year. We form annual returns by taking the product of intervening monthly returns. The annual price/dividend ratio is its value at the end of the year.

We report corresponding historical statistics with some trepidation. On the one hand, it is useful to get some quantitative idea of the target. On the other hand, the historical statistics are the subject of an enormous empirical literature, and the point estimates of simplified statistics from one particular sample do little justice to the econometric and data-handling sophistication of that literature. Also, estimates should be accompanied by standard errors, but useful measures of sampling uncertainty require a far more sophisticated analysis than space allows here. This is particularly true since our model suggests that peso problems will be important; stock returns in the model are nonnormally distributed and strongly influenced by the small possibility of a severe crash or depression.

\section{Means and Standard Deviations}

Table 2 presents means and standard deviations in simulated data, with the corresponding statistics from our two historical data sets. 
TABLE 2

Mfans and Standard Deviations of Simulated and Historical Data

\begin{tabular}{|c|c|c|c|c|}
\hline Statistic & $\begin{array}{c}\text { Consumption } \\
\text { Claim }\end{array}$ & $\begin{array}{l}\text { Dividend } \\
\text { Claim }\end{array}$ & $\begin{array}{l}\text { Postwar } \\
\text { Sample }\end{array}$ & $\begin{array}{c}\text { Long } \\
\text { Sample }\end{array}$ \\
\hline$E(\Delta c)$ & $1.89 *$ & & 1.89 & 1.72 \\
\hline$\sigma(\Delta c)$ & $1.22 *$ & & 1.22 & 3.32 \\
\hline$E\left(r^{f}\right)$ & $.094^{*}$ & & .094 & 2.92 \\
\hline$E\left(r-r^{\prime}\right) / \sigma\left(r-r^{\prime}\right)$ & $.43^{*}$ & .33 & .43 & .22 \\
\hline$E\left(R-R^{\prime}\right) / \sigma\left(R-R^{\prime}\right)$ & .50 & & .50 & \\
\hline$E\left(r-r^{\prime}\right)$ & 6.64 & 6.52 & 6.69 & 3.90 \\
\hline$\sigma\left(r-r^{\prime}\right)$ & 15.2 & 20.0 & 15.7 & 18.0 \\
\hline $\exp [E(p-d)]$ & 18.3 & 18.7 & 24.7 & 21.1 \\
\hline$\sigma(p-d)$ & .27 & .29 & .26 & .27 \\
\hline
\end{tabular}

Notk. - The model is simulated at a monthly frequency; statistics are calculated from aruficial time-averaged data at an annual frequency. All returns are annual percentages.

- Statistics that model parameters were chosen to replicate.

The first four moments match the postwar statistics exactly because we chose parameters to fit those moments. In particular, we picked the parameter $\gamma=2.00$ to exactly match the Sharpe ratio for log returns of 0.43 in postwar data. The model also matches the Sharpe ratio for simple returns of 0.50 . A $\gamma$ value of about four matches the dividend claim Sharpe ratio to the postwar value without much effect on other statistics.

We chose to match the postwar time series because they are a significantly harder target. The long historical time series feature a much larger standard deviation of consumption growth, a lower Sharpe ratio, and a higher risk-free rate. A $\gamma$ of about 0.7 matches the 0.22 Sharpe ratio for log returns in the long-term data, with little effect on the other statistics.

It is noteworthy that the model can match the mean and standard deviation of excess stock returns, with a constant low interest rate and a discount factor $\delta=0.89$ less than one, by any choice of parameters. These moments are the equity premium and risk-free rate puzzles, which we discuss below.

The remaining moments were not used to pick parameters, so we can use them to check the model's predictions. The choice of $\gamma$ matches the ratio of mean return to standard deviation, but it says nothing about the level of mean and standard deviation of returns. The ratio 0.43 could be generated by a mean of 0.43 percent and a standard deviation of 1 percent. In fact, the mean and standard deviation of excess returns are almost exactly equal to the corresponding values in the postwar data, using either the consumption claim or the dividend claim.

The mean price/dividend ratio is a bit below that found in post- 
war data, but this statistic is poorly measured because the price/ dividend ratio is highly serially correlated. The standard deviation of the price/dividend ratio is almost exactly the same as that found in the data. In this sense, the model accounts for the volatility of stock prices, a point we discuss in more detail below.

\section{Autocorrelations and Cross-Correlations}

Table 3 presents autocorrelations and table 4 presents cross-correlations from our simulated data, along with sample values from the historical data.

We picked the parameter $\phi$ to generate the .87 first-order annual autocorrelation of the price/dividend ratio seen in the table. Higher autocorrelations decay slowly, as in the data. The dividend claim has exactly the same autocorrelation pattern. This is not a surprise given that the dividend claim and consumption claim price/dividend ratios are almost identical.

Returns display a series of small negative autocorrelations that generate univariate mean reversion (Fama and French 1988b; Po-

TABLE 3

Autocorrelations of Simulated and Historical data

\begin{tabular}{|c|c|c|c|c|c|}
\hline \multirow[b]{2}{*}{ VARIABLE AND SOURCE } & \multicolumn{5}{|c|}{ LAC (Years) } \\
\hline & 1 & 2 & 3 & 5 & 7 \\
\hline \multicolumn{6}{|l|}{$p-d:$} \\
\hline Consumption claim & .87 & .76 & .66 & .51 & .39 \\
\hline Dividend claim & .87 & .76 & .66 & .51 & .39 \\
\hline Postwar sample & .87 & .77 & .70 & .41 & .04 \\
\hline Long sample & .78 & .57 & .50 & .32 & .29 \\
\hline \multicolumn{6}{|l|}{$r-r_{:}^{0}$} \\
\hline Consumption claim & -.06 & -.05 & -.04 & -.02 & -.02 \\
\hline Dividend claim & -.05 & -.04 & -.03 & -.02 & -.01 \\
\hline Postwar sample & -.11 & -.28 & .15 & .02 & .10 \\
\hline Long sample & .05 & -.21 & .08 & -.14 & .11 \\
\hline \multicolumn{6}{|l|}{$\sum_{i=1}^{i} \rho\left(r_{i}^{i}, r_{i-i}^{p}\right):^{*}$} \\
\hline Consumption claim & -.06 & -.11 & -.15 & -.20 & -.26 \\
\hline Dividend claim & -.05 & -.09 & -.12 & -.14 & -.18 \\
\hline Postwar sample & -.11 & -.39 & -.24 & .18 & .13 \\
\hline Long sample & .05 & -.16 & -.09 & -.28 & -.15 \\
\hline \multicolumn{6}{|l|}{$|r|:$} \\
\hline Consumption claim & .09 & .09 & .09 & .07 & .05 \\
\hline Dividend claim & .05 & .05 & .05 & .04 & .03 \\
\hline Postwar sample & .08 & -.26 & -.10 & -.08 & .05 \\
\hline Long sample & .13 & .09 & .07 & .14 & .15 \\
\hline
\end{tabular}

NotE. - The model values are based on time-aggregated annual values with a monthly simulation interval. All data are annual.

- Partial sum of return autocorrelations out to lag $j$. 
TABLE 4

Cross-Correlations of Simulated and Historical Data

\begin{tabular}{|c|c|c|c|c|c|}
\hline \multirow[b]{2}{*}{ VARIABLE AND SoURCE } & \multicolumn{5}{|c|}{ LAG (Years) } \\
\hline & 1 & 2 & 3 & 5 & 7 \\
\hline \multicolumn{6}{|l|}{$p_{t}-d_{b} r_{i+j}^{\prime}:$} \\
\hline Consumption claim & -.35 & -.30 & -.26 & -.20 & -.15 \\
\hline Dividend claim & -.28 & -.24 & -.20 & -.16 & -.12 \\
\hline Postwar sample & -.42 & -.25 & -.13 & -.35 & -.17 \\
\hline Long sample & -.20 & -.21 & -.10 & -.19 & -.08 \\
\hline \multicolumn{6}{|l|}{$r_{i}^{i},\left|r_{i+j}^{i}\right|:$} \\
\hline Consumption claim & -.09 & -.07 & -.06 & -.03 & -.03 \\
\hline Dividend claim & -.06 & -.04 & -.04 & -.03 & -.02 \\
\hline Postwar sample & -.32 & -.14 & .10 & -.04 & -.08 \\
\hline Long sample & -.15 & .03 & .12 & .02 & -.01 \\
\hline \multicolumn{6}{|l|}{$p_{1}-d_{i}\left|r_{i+j}^{i}\right|:$} \\
\hline Consumption claim & -.49 & -.42 & -.37 & -.28 & -.21 \\
\hline Dividend claim & -.36 & -.31 & -.27 & -.21 & -.16 \\
\hline Postwar sample & -.16 & .09 & .11 & -.05 & .02 \\
\hline Long sample & -.12 & .02 & -.06 & -.10 & -.05 \\
\hline
\end{tabular}

terba and Summers 1988). The negative autocorrelations of returns also generate observations that price changes tend to be reversed.

Since individual long-term autocorrelations are small and poorly measured, the empirical literature focuses on a number of clever statistics designed to better measure univariate mean reversion. One such statistic is the partial sum of autocorrelation coefficients, shown in the table. The model replicates the pattern and the rough (poorly measured) magnitude found in the data. The prewar data show a stronger mean-reverting pattern, which is a well-known feature of this statistic.

The autocorrelation of absolute returns reveals long-horizon conditional heteroskedasticity in the model. The ARCH literature (for a summary see Bollerslev et al. [1992]) finds higher values for these autocorrelations in high-frequency data but values similar to our first-order autocorrelation at annual frequencies. The ARCH literature has not noted the negative 2- and 3-year autocorrelations of absolute returns in the postwar data, but these findings may be artifacts of a simplistic technique or sampling error. The dividend claim has a lower autocorrelation of absolute returns since its return is a noisier indicator of changes in the surplus consumption ratio.

The cross-correlation between the price/dividend ratio and subsequent excess returns, shown in table 4 , verifies that the price/ consumption ratio forecasts long-horizon returns with the right sign: high prices forecast low returns. Since high prices forecast low returns for many years in the future, the forecastability of returns in- 
creases with the horizon, as we show next. The correlations are slightly smaller for the dividend claim since its return is slightly noisier.

The cross-correlations between the price/dividend ratio or returns and subsequent absolute returns show that a low price/consumption ratio or a big price decline signals high volatility for several years ahead. This is the "leverage effect" that Black (1976), Schwert (1989), Nelson (1991), and many others have found in the data. As with the univariate autocorrelation of absolute returns, the data seem to indicate a somewhat shorter-lasting change in conditional variance than is predicted by the model, at least as viewed by this simple statistic. Again, the dividend claim behaves much like the consumption claim, despite the very low .2 correlation of dividend growth with consumption growth.

\section{Long-Horizon Regressions}

Table 5 presents long-horizon regressions of log excess stock returns on the log price/dividend ratio in simulated and historical data. We use excess returns to emphasize that risk premia rather than riskfree rates vary over time. We see the classic pattern documented by Campbell and Shiller (1988b) and Fama and French (1988a). The coefficients are negative: high prices imply low expected returns. The coefficients increase linearly with horizon at first and then less quickly; the $R^{2}$ 's start low but then rise to impressive values. The model's predictions for the consumption claim match closely the postwar data. The coefficients for the dividend claim are about the same, but the $R^{2}$ 's do not rise as fast since the dividend claim return contains the extra dividend growth noise.

TABLE 5

LONG-HORIZON RETURN REGRESSIONS

\begin{tabular}{|c|c|c|c|c|c|c|c|c|}
\hline \multirow[b]{2}{*}{$\begin{array}{c}\text { HoRIzoN } \\
\text { (Years) }\end{array}$} & \multicolumn{2}{|c|}{$\begin{array}{c}\text { Consumption } \\
\text { Claim }\end{array}$} & \multicolumn{2}{|c|}{$\begin{array}{c}\text { Dividend } \\
\text { Claim }\end{array}$} & \multicolumn{2}{|l|}{$\begin{array}{c}\text { Postwar } \\
\text { SAMPLE }\end{array}$} & \multicolumn{2}{|c|}{ LONG SAMPLE } \\
\hline & $\begin{array}{c}10 \times \\
\text { Coefficient }\end{array}$ & $R^{2}$ & $\begin{array}{c}10 \times \\
\text { Coefficient }\end{array}$ & $R^{2}$ & $\begin{array}{c}10 \times \\
\text { Coefficient }\end{array}$ & $R^{2}$ & $\begin{array}{c}10 \times \\
\text { Coefficient }\end{array}$ & $R^{2}$ \\
\hline $\begin{array}{l}1 \\
2 \\
3 \\
5 \\
7\end{array}$ & $\begin{array}{l}-2.0 \\
-3.7 \\
-5.1 \\
-7.5 \\
-9.4\end{array}$ & $\begin{array}{l}.13 \\
.23 \\
.32 \\
.46 \\
.55\end{array}$ & $\begin{array}{l}-1.9 \\
-3.6 \\
-5.0 \\
-7.3 \\
-9.2\end{array}$ & $\begin{array}{l}.08 \\
.14 \\
.19 \\
.26 \\
.30\end{array}$ & $\begin{array}{r}-2.6 \\
-4.3 \\
-5.4 \\
-9.0 \\
-12.1\end{array}$ & $\begin{array}{l}.18 \\
.27 \\
.37 \\
.55 \\
.65\end{array}$ & $\begin{array}{l}-1.3 \\
-2.8 \\
-3.5 \\
-6.0 \\
-7.5\end{array}$ & $\begin{array}{l}.04 \\
.08 \\
.09 \\
.18 \\
.23\end{array}$ \\
\hline
\end{tabular}


Volatility Tests

Papers in the volatility test literature have found that stock prices move far more than can be explained by varying expectations of dividend growth and interest rates. In our model, expected dividend growth and the riskless interest rate are constant over time, so they explain none of the variation in stock prices. Therefore, the model implies an extreme version of the volatility test results.

To demonstrate this point, we replicate a volatility test in Cochrane (1992), which is closely related to the tests in Campbell and Shiller $(1988 a)$. A log-linearization of the accounting identity $1=$ $R_{t+1}^{-1} R_{t+1}$, with $R_{t+1}=\left(P_{t+1}+D_{t+1}\right) / P_{t}$, implies that, in the absence of rational asset price bubbles,

$$
\begin{aligned}
\operatorname{var}\left(p_{t}-d_{t}\right) \approx & \sum_{j=1}^{\infty} \rho^{j} \operatorname{cov}\left(p_{t}-d_{t}, \Delta d_{t+j}\right) \\
& -\sum_{j=1}^{\infty} \rho^{j} \operatorname{cov}\left(p_{t}-d_{t}, r_{t+j}\right),
\end{aligned}
$$

where $\rho \equiv(P / D) /[1+(P / D)]$ and $P / D$ is the point of linearization. The price/dividend ratio can vary only if it sufficiently forecasts dividend growth or returns or both.

Table 6 presents estimates of (21), using 15 years of covariances to estimate the sums in artificial data and in the two data samples. The point estimates in the data find that more than 100 percent of the price/dividend ratio variance is attributed to expected return variation. A high price/dividend ratio signals a decline in subsequent real dividends, so it must signal a large decline in expected returns. The forecast dividend decline is not statistically different from zero,

TABLE 6

VARIANCE Decompositions

\begin{tabular}{lcc}
\hline \hline Source & Returns (\%) & Dividends (\%) \\
\hline Consumption claim & 100 & 1 \\
Dividend claim & 99 & 3 \\
Postwar sample & 137 & -31 \\
Long sample & 101 & -10 \\
\hline
\end{tabular}

Note.-Table entries are the percentage of $\operatorname{var}(p-d)$ accounted for by dividend growth and returns,

$$
100 \times \sum_{j=1}^{19} \frac{\rho^{\prime} \operatorname{cov}\left(p_{t}-d_{t,} x_{t+j}\right)}{\operatorname{var}\left(p_{t}-d_{t}\right)}
$$

$x=-r$ and $\Delta d$, respectively. 
however. All of the price/dividend ratio variance is accounted for, providing evidence against the view that stock market volatility is driven by rational bubbles.

In the model, all variation in the price/dividend ratio is due to changing expected returns by construction. To within the accuracy of the log-linear approximation, the variance decomposition on artificial data reflects this fact.

The Correlation of Consumption Growth with Stock Returns

Equilibrium consumption-based models typically imply that consumption growth and stock returns are highly, if not perfectly, correlated. For example, with log utility, the return on the wealth portfolio equals consumption growth, ex post, data point for data point. This implication is the basis for many theoretical models in finance that substitute portfolio returns for consumption growth. However, this implication is seldom checked or used to test asset pricing models, for the obvious reason that it is dramatically false. As Cochrane and Hansen (1992) emphasize, the actual low correlation between stock returns and consumption growth lies at the heart of many empirical failures of the consumption-based model.

In our model, consumption growth and consumption claim returns are conditionally perfectly correlated since consumption growth is the only source of uncertainty. But the relation between consumption growth and returns varies over time with the surplus consumption ratio. Hence the unconditional correlation between consumption growth and returns is not perfect. Panel $a$ of figure 7 shows this effect of conditioning information by plotting artificial data on monthly consumption growth versus returns. For a given surplus consumption ratio, such pairs lie on a line, but the slope of the line changes as the surplus consumption ratio changes. Therefore, the consumption-return pairs fill a region bounded by two straight lines, each of which corresponds to one limit of the surplus consumption ratio.

Panel $b$ of figure 7 plots the correlation of consumption growth with returns in simulated annual data. As the figure shows, time aggregation further degrades the perfect conditional correlation between consumption growth and returns.

Table 7 presents several measures of the correlation between consumption growth and stock returns. In the data, there is very little contemporaneous correlation between consumption growth and returns. However, returns are negatively correlated with previous consumption growth and positively correlated with subsequent con- 


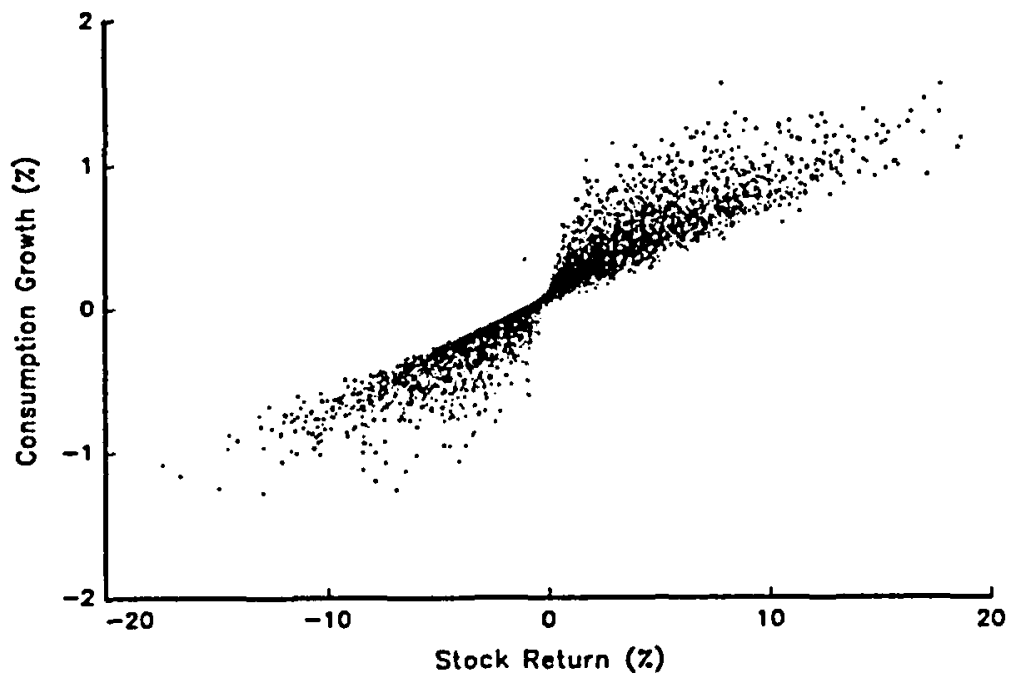

b

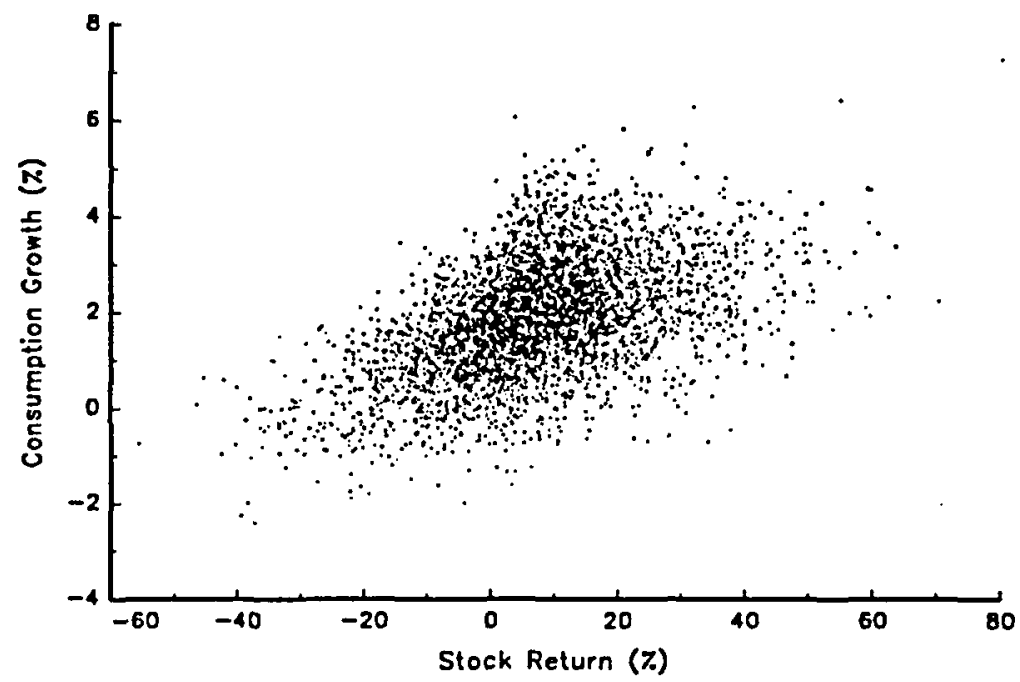

Fic. 7.- $a$, Simulated monthly consumption growth vs. monthly consumption claim returns. $b$, Growth in simulated annual consumption vs. annual consumption claim returns. 


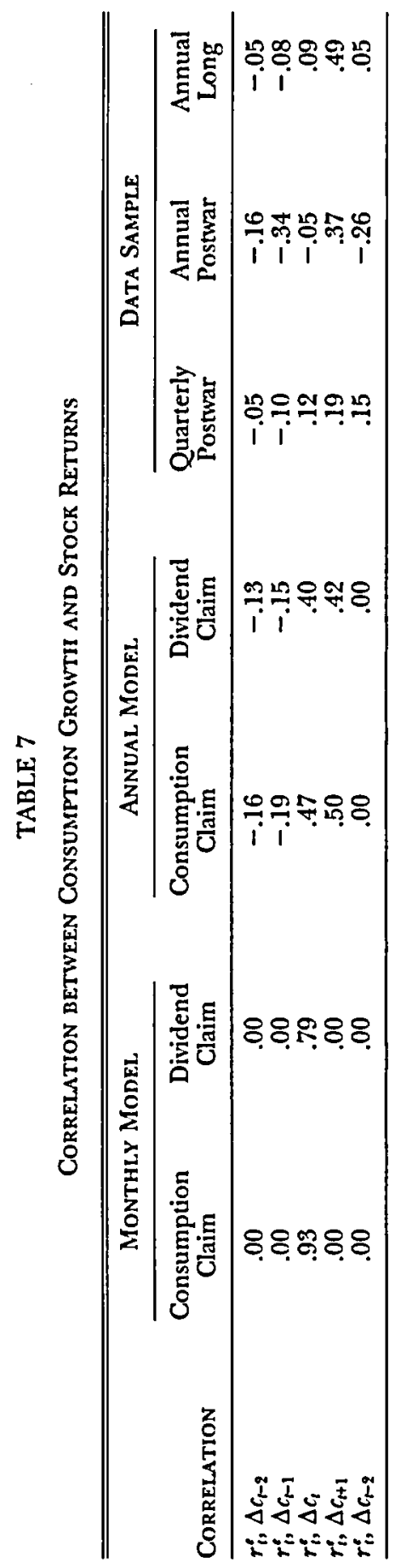

Copyright (c 1999. All rights reserved. 
sumption growth. The highest correlations occur between returns and the next year's consumption growth: .37 in postwar data and .49 in long-term data. Fama (1990) interprets similar correlations of returns with output as evidence that returns move on news of future cash flows.

In our model, the unconditional correlation between monthly consumption claim returns and monthly consumption growth is $\mathbf{9 3}$. This value corresponds to panel $a$ of figure 7 . It is less than the 1.0 of the standard time-separable model but much greater than the correlations we see in the data. In addition, there is no correlation between returns and consumption growth at any lead or lag.

When we time-aggregate the artificial data to annual frequencies, the contemporaneous correlation drops to .47. Furthermore, time aggregation produces a strong positive correlation between returns and subsequent consumption growth and a negative correlation between returns and previous consumption growth, the same sign pattern that we see in the data.

Modeling stocks as a dividend claim further reduces the correlations. Since the correlation of dividend growth with consumption growth is only .2, one might expect still lower correlations. But again most return variation is driven by price variation, so the extra dividend volatility has a relatively small effect.

Thus the varying conditioning information in our model together with an explicit accounting for time aggregation goes a long way toward resolving the puzzling low correlation of consumption growth with returns and toward explaining the correlation between returns and subsequent macroeconomic variables. Adding state variables and accounting for lags and errors in data collection are likely to further help to account for the correlations of consumption with asset returns.

\section{The Correlation of the Discount Factor with}

\section{Consumption Growth and Stock Returns}

The static capital asset pricing model (CAPM) often does a better job of accounting for risk premia than the consumption-based asset pricing model with power utility (Mankiw and Shapiro 1986). It turns out that this is true in our artificial data as well, even though the data are generated by a consumption-based model. Campbell and Cochrane (1998b) present detailed calculations. We show the basic point here by calculating the correlation between the true stochastic discount factor and consumption growth or stock returns. Discount factor proxies that are better correlated with the true discount factor produce smaller pricing errors for a given set of assets. 


\section{TABLE 8}

Correlation of tile Stochastic Discount Factor with

Consumption Growth, Consumption Claim Return, and Dividend Claim Return

\begin{tabular}{lccc}
\hline \hline & \multicolumn{3}{c}{ Correlation of Stochastic Discount Factor witr: } \\
\cline { 2 - 4 } & $\begin{array}{c}\text { Consumption } \\
\text { Growth }\end{array}$ & $\begin{array}{c}\text { Consumption Claim } \\
\text { Return }\end{array}$ & $\begin{array}{c}\text { Dividend Claim } \\
\text { Return }\end{array}$ \\
\hline Monthly & .90 & .99 & .83 \\
Annual & .45 & .99 & .80 \\
\hline
\end{tabular}

Note. - The stochastic discount factor is

$$
M_{t+1}=\delta\left(\frac{C_{t+1}}{C_{t}} \frac{S_{t+1}}{S_{t}}\right)^{-\gamma}
$$

Table 8 presents the correlations. In monthly artificial data, the consumption claim return is far better correlated with the true discount factor than consumption growth is. Therefore, the static CAPM using the "wealth portfolio" return is a better approximate model. Although the discount factor is conditionally perfectly correlated with consumption growth, the unconditional correlation is low because the surplus consumption ratio varies. The stock return moves when the surplus consumption ratio changes and hence reveals more of the discount factor movement.

We might expect the relative performance of the consumptionbased model to deteriorate further at longer horizons. At longer horizons, there is more movement of the surplus consumption ratio independent of consumption growth, and this movement will be revealed by stock return variation since stock prices decline when the surplus consumption ratio declines. Time aggregation further obscures the consumption signal. Table 8 confirms this intuition: at an annual frequency the correlation of the discount factor with timeaveraged consumption growth has declined to .45 , whereas the correlation with the consumption claim return is still .99 .

At a monthly horizon, the dividend claim return is a poorer proxy than even consumption growth because dividend growth contains noise not correlated with the discount factor. When we go to a longer horizon and introduce time aggregation in consumption, however, even the dividend claim return is a far better proxy for the discount factor than consumption growth. These annual results are the relevant ones because actual monthly consumption data, unlike the simulated monthly consumption data, are time-averaged and measured with error. 


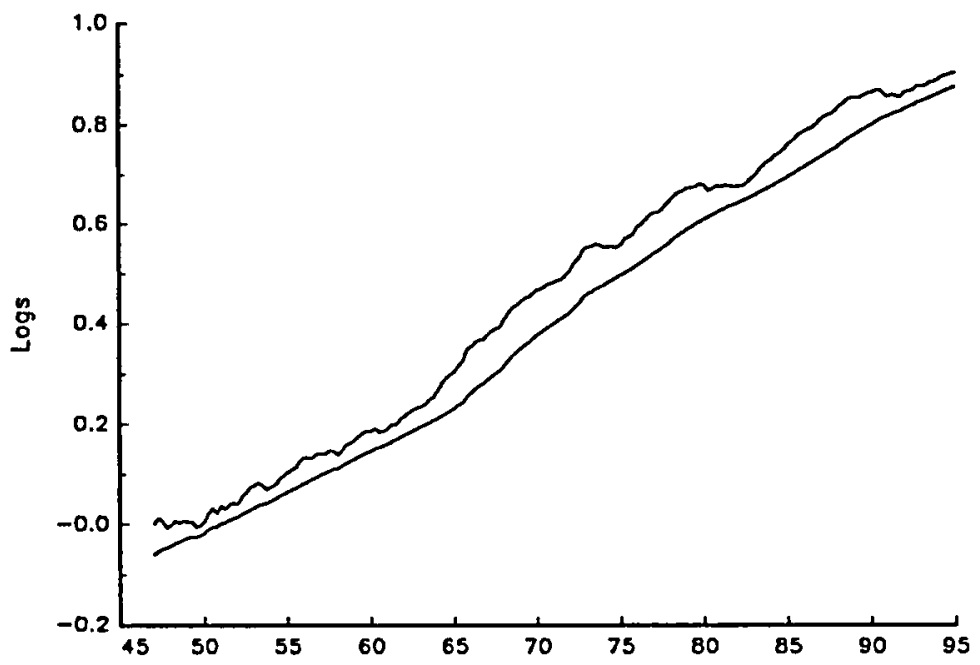

Fic. 8.-Nondurable and services consumption per capita and habit level implied by the model, under the assumption that the surplus consumption ratio starts at the steady state.

\section{Interpreting Historical Consumption and Stock Price Data}

Instead of simulating artificial consumption data, we now feed our model actual data on nondurables and services consumption per capita. Figure 8 presents the postwar history of consumption and the habit level implied by our model, assuming that habit starts at the steady state at the beginning of the sample.

The figure shows how habit responds smoothly to changes in consumption, trending up in the high-growth 1960 s and growing more slowly in the 1970 s. Cyclical dips in consumption bring consumption closer to habit. Our model will predict low price/dividend ratios and high expected returns for those periods.

Figure 9 presents the model's prediction for the price/dividend ratio of a consumption claim, together with the actual price/dividend ratio on the S \& $P 500$ index. The prewar prediction is based on a calibration of the model to the long data set; it uses the lower mean and higher standard deviation of consumption growth of those data and a lower value of $\gamma=0.7$ to generate the lower Sharpe ratio in that data set. We emphasize that the "model" line on the graph is produced using only consumption data and no asset market data. A similar graph using the dividend claim rather than the consumption claim is almost identical since the predicted price/divi- 


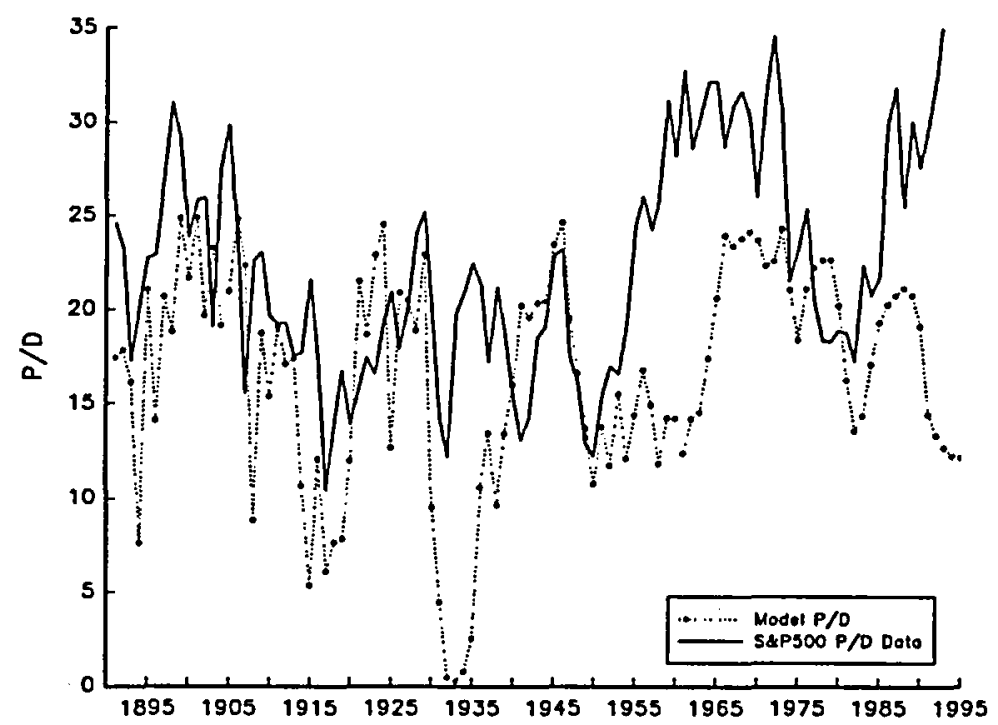

FIc. 9.-Historical price/dividend ratio and model predictions based on the history of consumption.

dend ratio of the dividend claim is almost exactly the same function of state as the price/dividend ratio of the consumption claim.

To our eyes, the model provides a tantalizing account of cyclical and longer-term fluctuations in stock prices. When consumption declines for several years in a row, coming nearer to our constructed habit, stock prices fall. Model and actual price/dividend ratios fall in the sharp recessions of the late nineteenth and early twentieth centuries, and the model also captures the long-term rise and then decline from 1890 to 1915 . The model accounts for the boom of the 1920s. The decline in consumption in the Great Depression was so extreme that the model predicts an even larger fall in stock prices than actually occurred. Then the model tracks the recovery during World War II, the consumption and stock boom of the 1960s (though with a lag), the secular and cyclical declines of the 1970s, and the consumption and stock market boom of the 1980s.

It is a little embarrassing that the worst performance occurs in the last few years. Growth in consumption of nondurables and services was surprisingly slow in the early 1990s, bringing consumption near our implied habit level (fig. 8), so our model predicts a fall in price/ dividend ratios rather than the increase we see in the data. Possible excuses include a shift in corporate financial policy toward the repurchase of equity rather than dividend payments; an increase in the consumption of stock market investors that is not properly cap- 
tured in the aggregate consumption data, due perhaps to rising income inequality in the period or the demographic effects of the baby boom generation entering peak saving years; and measurement problems such as compositional shifts of consumption away from nondurables and services.

\section{Model Intuition}

The Equity Premium and Risk-Free Rate Puzzles

Our model is consistent with the equity premium and a low and constant risk-free rate. It is worth seeing how the model resolves these long-standing puzzles.

With power utility $M_{t+1}=\beta\left(C_{t+1} / C_{t}\right)^{-\pi}$, a constant risk-free rate, and i.i.d. lognormal consumption growth with mean $g$ and standard deviation $\sigma$, the Hansen-Jagannathan or Sharpe ratio inequality (6) specializes to

$$
\frac{E\left(R^{e}\right)}{\sigma\left(R^{e}\right)} \leq \sqrt{e^{\eta^{2} \sigma^{2}}-1} \approx \eta \sigma
$$

and the $\log$ interest rate is

$$
r_{t}^{f}=-\ln (\beta)+\eta g-\eta^{2} \frac{\sigma^{2}}{2} .
$$

To explain a (gross return) Sharpe ratio of 0.50 with $\sigma=1.22$ percent, the power utility model needs a risk aversion coefficient $\eta \geq 41$ by equation (22). This is Mehra and Prescott's (1985) "equity premium puzzle." One can object to $\eta \geq 41$ as an implausibly large value of risk aversion, and we discuss this interpretation below.

More important, a high value of $\eta$ makes the term $\eta g$ in the riskfree rate equation very large. Thus $\eta=41$ and $g=1.89$ percent means that we need $\beta=1.90$ to get a 1 percent risk-free rate. Imposing $\beta \leq 1$, one predicts a risk-free rate of more than 90 percent per year! Weil (1989) emphasizes this "risk-free rate puzzle," and Cochrane and Hansen (1992) discuss the level and variability of riskfree interest rates in high-risk aversion models.

Despite its intuitive implausibility, one might argue that setting $\beta=1.90$ resolves the risk-free rate puzzle. However, with $\beta=1.90$ and $\eta=41$, equation (23) implies that the risk-free interest rate should be quite sensitive to the mean consumption growth rate, which is not the case. Real interest rates do not vary across time or countries by 40 times the variation in predicted or average consumption growth. (Equivalently, one must assume wild cross-country vari- 
ation in patience $\beta$ to save the model. Campbell [1999] reports such estimates.)

Our model also features high curvature. Though the power $\gamma=$ 2 is low, the surplus consumption ratio is also low. So local curvature $\eta=-C u_{c c} / u_{c}=\gamma / S$ is high: 35 at the steady state and higher still in states with low surplus consumption ratios. However, our model does not predict a sensitive relation between consumption growth and interest rates. Equation (12),

$$
r_{t}^{f}=-\ln (\delta)+\gamma g-\left(\frac{\gamma}{\bar{S}}\right)^{2} \frac{\sigma^{2}}{2}
$$

shows that the power parameter $\gamma=2$, much lower than utility curvature $\gamma / S$, controls the relationship between average consumption growth and the risk-free interest rate.

Thus we avoid the risk-free rate puzzle: an intuitively plausible $\delta=0.89<1$ is consistent with the low observed real interest rate; and the model predicts a much less sensitive relationship across countries or over time between mean consumption growth and interest rates. Furthermore, the time-varying risk-free rate version of our model (Campbell and Cochrane 1995) produces a risk-free rate that varies over time as a function of the surplus consumption ratio, whereas consumption growth is i.i.d. Therefore, this model predicts no time-series relationship at all between interest rates and expected consumption growth rates, consistent with the great difficulty the empirical literature has found in documenting any such relation in the data.

In order to remove the tension between equity premia as in (22) and risk-free rates as in (23), our model uses non-time-separable preferences to distinguish intertemporal substitution and risk aversion. Weil (1989), Epstein and Zin (1991), Kandel and Stambaugh (1991), and Campbell (1996) use non-state-separable preferences to the same effect but do not generate time-varying risk aversion.

Our solution to the risk-free rate puzzle has one other important advantage. Abel (1999) highlights the danger of accounting for an equity premium by a term premium. If a model assigned a high premium to the interest rate exposure of stock cash flows and longterm bond cash flows alike, it would account for the equity premium of stocks over short-term bonds, but it would counterfactually predict high expected returns for long-term bonds as well. Since interest rates are constant in our model, long-term bonds earn exactly the same returns as short-term bonds, and the entire equity premium is a risk premium, not a term premium. 
The Long-Run Equity Premium

The equity premium puzzle is a feature of long as well as short horizons. Consumption is roughly a random walk at any horizon, so the standard deviation of consumption growth grows roughly with the square root of the horizon. The negative autocorrelation of stock returns means that $k$-year return variances are somewhat less than $k$ times 1-year return variances, so the market Sharpe ratio grows, if anything, faster than the square root of the horizon (MaCurdy and Shoven 1992; Siegel 1994; Campbell 1996).

In our model, the $k$-period stochastic discount factor is

$$
M_{t, t+k}=\delta^{k}\left(\frac{S_{t+k}}{S_{t}} \frac{C_{t+k}}{C_{t}}\right)^{-\gamma} .
$$

Equation (6) implies that the standard deviation of this discount factor must increase roughly with the square root of the horizon to be consistent with the long-run equity premium, and even faster to generate the negative autocorrelation of stock returns.

One can think of our model as a member of a large class that adds a new state variable $S_{t+1}$ to the discount factor. However, most extra state variables-such as recessions, labor, and instruments for timevarying expected returns ("shifts in the investment opportunity set") - are stationary. Hence, the standard deviation of their growth rates eventually stops growing with horizon. At a long enough horizon, the standard deviation of the discount factor is dominated by the standard deviation of the consumption growth term, and we return to the equity premium puzzle at a long enough run. One could of course (and many models that explain the short-run equity premium do so) posit positive serial correlation in consumption growth, so that long-run consumption growth is much more volatile than annual consumption growth. But we do not see this in the data.

Our model has a pure random walk in consumption, yet it produces negative autocorrelation in returns and therefore high Sharpe ratios at all horizons. How does it accomplish this feat with a stationary state variable $S_{l}$ ? The answer is that while $S_{t}$ is stationary, $S_{t}^{-\gamma}$ is not. The variable $S_{t}$ has a fat tail approaching zero (see fig. 2), so the conditional variance of $S_{t+k}^{-\gamma}$ grows without bound. We can demonstrate this behavior using the formula for the distribution of $S$ given in the appendix (Campbell and Cochrane 1998a): As $s \rightarrow-\infty$, the leading terms in the distribution are

$$
f(s) \approx e^{-\gamma|s|-2 \gamma \sqrt{2] s}} \text {. }
$$


We can integrate polynomials multiplied by this expression, so $s$ is a covariance-stationary process with a well-defined unconditional mean, variance, and all higher moments. The surplus consumption ratio $S=e^{s}$ is also well behaved. However, while $S^{-\gamma}$ has a finite unconditional mean, since $e^{-\gamma_{s}} f(s)$ is integrable, $s^{-\gamma}$ does not have a finite unconditional variance since $e^{-2 \gamma s} f(s) \approx e^{\gamma|s|}$ explodes as $s \rightarrow-\infty$.

While the distinction between stationary $S$ and nonstationary $S^{-\gamma}$ seems initially minor, it is in fact central. Any model that wishes to explain the equity premium at long and short runs by means of an additional, stationary state variable must find some similar transformation so that the equity premium remains high at long horizons.

\section{A Recession State Variable}

Equation (24) emphasizes that our model makes a fundamental change in the way we understand risk premia. Consumers do not fear stocks because of the resulting risk to wealth or to consumption per se; they fear stocks primarily because stocks are likely to do poorly in recessions, times of low surplus consumption ratios. While $\left(C_{t+1} / C_{t}\right)^{-\gamma}$ and $\left(S_{t+1} / S_{t}\right)^{-\gamma}$ enter symmetrically in the formula, the volatility of $\left(C_{t+1} / C_{t}\right)^{-\gamma}$ is so low that it accounts for essentially no risk premia. The volatility of $\left(S_{t+1} / S_{t}\right)^{-\gamma}$ is much larger and accounts for nearly all risk premia. Variation across assets in expected returns is driven by variation across assets in covariances with recessions far more than by variation across assets in covariances with consumption growth.

At short horizons, $S_{t+1}$ and $C_{t+1}$ move together, so the distinction between a recession state variable and consumption risk is minor; one can regard $S$ as an amplification mechanism for consumption risks in marginal utility. At long horizons, however, $S_{t+k}$ becomes less and less conditionally correlated with $C_{t+k} ; S_{t+k}$ depends on $C_{t+k}$ relative to its recent past, but the overall level of consumption may be high or low. Therefore, in contrast to Rietz's (1988) model of a small probability of a very large negative consumption shock, investors fear stocks because they do badly in occasional serious recessions unrelated to the risks of long-run average consumption growth.

\section{Nonstochastic Analysis}

It is common in growth theory to abstract from uncertainty and compare data from actual economies to the predictions of nonstochastic models. Many stochastic business cycle models study small deviations from nonstochastic steady states, which are thought to describe 
means well. Our model offers an interesting laboratory to study the accuracy of this sort of approximation.

Equation (8) for the risk-free rate,

$$
r_{t}^{f}=-\ln (\delta)+\gamma g-\gamma(1-\phi)\left(s_{t}-\bar{s}\right)-\frac{\gamma^{2} \sigma^{2}}{2}\left[1+\lambda\left(s_{t}\right)\right]^{2},
$$

highlights one important danger of nonstochastic analysis. In our model, the second to last intertemporal substitution term exactly offsets the last precautionary savings term in order to produce a constant interest rate. In the absence of the precautionary savings effect of a changing $\lambda\left(s_{t}\right)$, interest rates would vary a great deal with the state variable $s_{t}$ in our model. A researcher who analyzed data from our economy with a nonstochastic version of the model would be puzzled by the stability of the risk-free interest rate. Precautionary savings are not a second-order effect.

A nonstochastic analysis also has trouble with the fact that price/ dividend ratios are finite. At our parameter values, the consumption growth rate (1.89 percent) is about double the interest rate $(0.94$ percent). Thus a risk-neutral or certainty version of our economy predicts an infinite price of the consumption and dividend streams. Only the risk-corrected prices are finite.

\section{Some Microeconomic Implications}

In this section, we address several of the most important objections to the model: that it seems not to allow for any heterogeneity across consumers, that it assumes implausibly high risk aversion, and that it relies on an external-habit rather than the more common internal-habit specification.

At heart, all three objections have to do with the potential application of the model to microeconomic data. This is not our chief concern in this paper. Our goal, ambitious enough, is to find representative-agent preferences that explain the joint behavior of aggregate consumption and stock returns. These representative-agent preferences could take the same form as the underlying preferences of individual agents, but they could also result from aggregation of heterogeneous consumers with quite different preferences. As one example, Constantinides and Duffie (1996), building on Mankiw (1986), show how to disaggregate any representative-agent marginal utility process, including ours, to individual agents with power utility and low risk aversion in incomplete markets by allowing the crosssectional variance of idiosyncratic income to vary with the posited marginal utility process. Nonetheless, we find external habit forma- 
tion appealing as a description of individual preferences, and the representative-agent model is clearly more compelling if its preferences can result from aggregation of individuals with similar preferences. Therefore, we now briefly consider whether the external habit model makes sense for microeconomic data.

\section{A. Heterogeneity}

Our identical-agent model, with parameter values such that habit is only about 5 percent below consumption, seems initially to be inconsistent with cross-sectional variation in wealth and consumption. If everyone has the same habit level, then poor people with consumption more than 5 percent below average would have consumption below habit, which makes no sense in our power specification.

In fact, however, our model can at least aggregate under complete markets with heterogeneous agents and heterogeneous groups. While these aggregation results are not as general as one might like-a standard problem in representative-agent models-it is still reassuring that many of the simple aggregation arguments for power utility apply, so the model is not automatically inconsistent with the wide cross-sectional variation of individual consumption and wealth. As usual in such results, the trick is to maintain identical growth in marginal utility while allowing some heterogeneity across individuals in levels of consumption, utility, or marginal utility.

We can allow many different reference groups with different levels of wealth by letting each agent's habit be determined by the average consumption of his reference group rather than by average consumption in the economy as a whole. Then poor people with low consumption levels have the same surplus consumption ratio as rich people with high consumption, since their reference groups also have low consumption. Each agent still has an identical power utility function of the difference between his consumption and his habit, and each group's consumption growth still moves in lockstep. With identical surplus consumption ratios and consumption growth rates, marginal utility growth is unchanged despite the heterogeneity in group consumption levels. In the appendix (Campbell and Cochrane $1998 a$ ), we show algebraically that the representative-agent preferences are the same as those of the individuals in this economy.

We can also allow some individual heterogeneity. Suppose that each agent $i$ receives an endowment $C_{l}^{i}$, which is determined from the aggregate endowment $C_{t}^{a}$ by

$$
C_{t}^{i}=\left(\frac{\xi_{i}}{\xi}\right)^{1 / \gamma}\left(C_{t}^{a}-X_{t}\right)+X_{t} .
$$


The weights $\xi_{i}$ vary across individuals, and $X_{i}$ is determined from the history of aggregate consumption via (3) as usual. By construction of the example, marginal utility $\left(C_{t}^{i}-X_{i}\right)^{-\gamma}$ is proportional across agents, so marginal utility growth is the same for all individuals despite the heterogeneity in consumption levels. Therefore, all individuals agree on asset prices and have no incentive to trade away from their endowments. To complete the example, we show in the appendix (Campbell and Cochrane 1998a) that $C_{b}^{a}$ is in fact the average of $C_{i}^{i}$ in each period. The combination of group and individual heterogeneity is straightforward, if algebraically unpleasant.

\section{B. Risk Aversion}

Do we achieve a model consistent with the historical equity premium by assuming implausibly high values of risk aversion? We have emphasized an interpretation of the "equity premium puzzle" in terms of aggregate observations: high risk aversion is undesirable in power utility models because it leads to counterfactual predictions for interest rates and consumption growth, and our model resolves these problems. But many people object to high risk aversion per se, even if it is consistent with all data on asset prices and economic aggregates. This objection is therefore also fundamentally a concern about microeconomic evidence.

Most intuition about risk aversion comes from surveys of indiviclual attitudes toward bets on wealth (including introspection, which is a survey with a sample size of one). But survey evidence for low risk aversion can be hard to interpret. To avoid the implication that we are all risk neutral to small zero-beta bets, surveys focus on very large bets on wealth, outside ordinary experience, that consumers may reasonably have trouble digesting. Building on this observation, Kandel and Stambaugh (1991) subject some common thought experiments to a careful sensitivity analysis and show that high risk aversion is not as implausible as one might have believed. As is often the case, existing empirical microeconomic evidence does not give precise measurements for input into macroeconomic models.

The agents in our model do display high risk aversion. However, we argue that high risk aversion is inescapable (or at least has not yet been escaped) in the class of identical-agent models that are consistent with the equity premium facts at short and long runs.

Risk aversion measures attitudes toward pure wealth bets and is therefore conventionally captured by the second partial derivative of the value function with respect to individual wealth, with any other state variables held constant. In the appendix (Campbell and Cochrane 1998a), we define the value function for an individual in 
our economy. The value function depends on individual wealth $W$ and on aggregate variables that describe asset prices or investment opportunities and the level of the external habit. We write it as $V\left(W_{\imath}, W_{\imath}^{a}, S_{\imath}^{a}\right)$. Risk aversion is defined as the elasticity of value with respect to individual wealth:

$$
r r a_{t} \equiv-\frac{W V_{W W}}{V_{W}}=-\frac{\partial \ln V_{W}(\cdot)}{\partial \ln W} .
$$

Risk aversion, defined in this way, plays no direct role in describing our model at the aggregate level. Individual wealth, aggregate wealth, and the surplus consumption ratio always move together, so all partial derivatives of the value function are involved in generating asset prices. Risk aversion is potentially interesting only in a reconciliation with microeconomic data.

In the appendix (Campbell and Cochrane 1998a) we calculate risk aversion for our model. Risk aversion is about 80 at the steady state (twice the curvature of about 40 ), rises to values in the hundreds for low surplus consumption ratios, and is still as high as 60 at the maximum surplus consumption ratio. Thus risk aversion is countercyclical, like utility curvature, and it is actually higher than utility curvature everywhere. This result can be understood as follows. The envelope condition $u_{c}=V_{W}$ implies that risk aversion can be written as utility curvature times the elasticity of consumption to individual wealth, with aggregates held constant:

$$
r a_{t}=-\frac{\partial \ln V_{w}(\cdot)}{\partial \ln W_{t}}=\frac{\partial \ln u_{c}(\cdot)}{\partial \ln C_{t}} \times \frac{\partial \ln C_{t}}{\partial \ln W_{t}}=\eta_{t} \frac{\partial \ln C_{t}}{\partial \ln W_{t}} .
$$

If date $t$ consumption moves proportionally to an individual wealth shock, risk aversion is the same as utility curvature. In our model, consumption rises more than proportionally to an increase in idiosyncratic wealth, so risk aversion $r a_{t}$ is larger than curvature $\eta_{t}$. An increase in individual wealth allows the individual to permanently increase his individual consumption over habit. This increase reduces the consumer's precautionary savings, implying that consumption increases more than proportionally at first. The consumer finances the extra initial consumption by increasing consumption less than proportionally to the initial wealth shock in subsequent states with high curvature and hence high contingent claim value.

Constantinides (1990) and Boldrin, Christiano, and Fisher (1996) present models with low risk aversion that are consistent with the equity premium and low consumption volatility at short horizons. In these models, consumers adjust consumption slowly after an idiosyncratic wealth shock. The term $\left(\partial \ln C_{t}\right) /\left(\partial \ln W_{l}\right)$ in (25) is low, 
so risk aversion is lower than the utility curvature that generates high Sharpe ratios through the Hansen-Jagannathan logic. However, the slow and predictable rise in consumption following a wealth shock means that these models do not fit the long-run properties of the data. They match high long-run Sharpe ratios with high long-run consumption volatility, volatility as high as that of returns. So far, no representative-agent expected utility model with low risk aversion is consistent with high Sharpe ratios and low consumption growth volatility at both short and long horizons.

\section{Internal Habit Formation}

So far we have specified an external habit: habits are set by everyone else's consumption. There are two reasons to calculate marginal utility and asset prices under the assumption that habits are internal rather than external. First, one wants to check whether the social marginal utility of consumption is always positive, despite the externality. Second, it is interesting to know whether the external-habit specification is essential to the results or whether it is just a convenient simplification.

It is possible that external rather than internal habits make little difference to aggregate consumption and asset pricing implications. With internal habits, consumption today raises future habits, lowering the overall marginal utility of consumption today. But asset prices are determined by ratios of marginal utilities. If internal habits simply lower marginal utilities at all dates by the same proportion, then a switch from external to internal habits has no effect on allocations and asset prices. For example, we show in the appendix (Campbell and Cochrane 1998a) that this occurs with power utility $(C-X)^{1-\gamma}$, a constant interest rate, and linear habit accumulation $X_{t}=\theta \sum_{j=1}^{\infty} \phi^{i} C_{t-j . j}$. Hansen and Sargent (1998) provide a similar example.

Our model adopts a nonlinear habit accumulation equation to generate an exact random walk in consumption along with a constant risk-free rate. (In the linear habit example above, consumption is close to but not exactly a random walk.) The nonlinearity in the habit accumulation process is thus the only reason there is any difference between the internal-habit and external-habit specification of our model. Still, it is interesting to know how big this difference is.

When habit is internal, marginal utility at time $t$ in our model has extra terms reflecting the effect of time $t$ consumption on time $t+j$ habits:

$$
M U_{t}=\frac{\partial U_{t}}{\partial C_{t}}=\left(C_{t}-X_{t}\right)^{-\gamma}-E_{t}\left[\sum_{j=0}^{\infty} \delta^{j}\left(C_{t+j}-X_{t+j}\right)^{-\gamma} \frac{\partial X_{t+j}}{\partial C_{t}}\right] .
$$




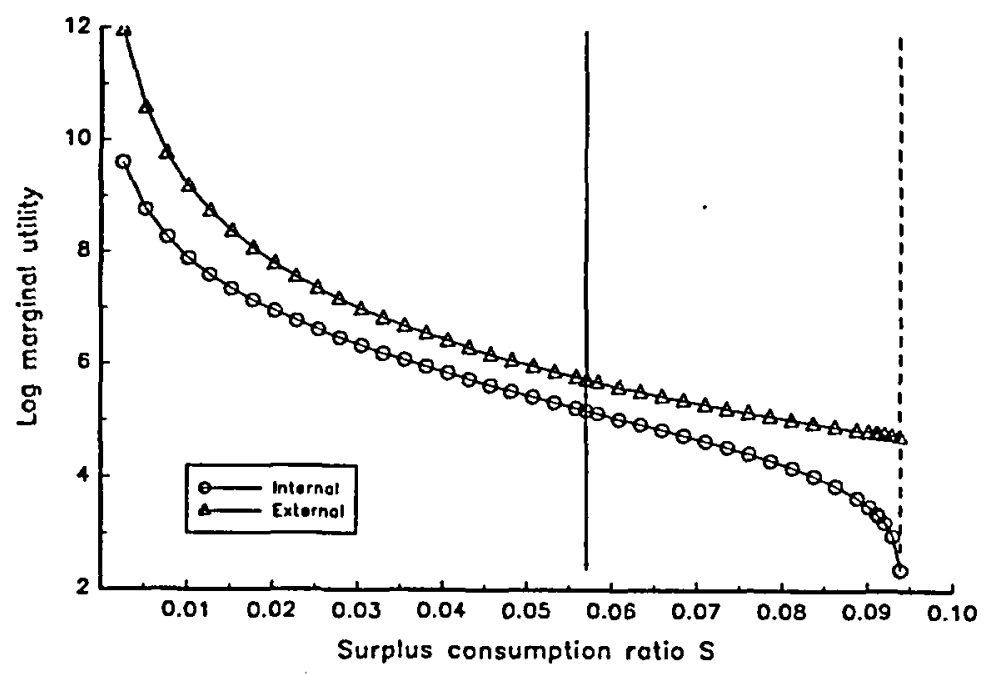

Fig. 10.-Marginal utility with internal vs. external habits. In each case, the marginal utility of consumption is given by $M U_{t}=C_{t}^{-\gamma} f\left(S_{t}\right)$; the figure plots $f\left(S_{t}\right)$.

In the appendix (Campbell and Cochrane 1998a) we show how to calculate marginal utility for the internal-habit version of our model, closed as an endowment economy with random walk consumption.

Figure 10 plots marginal utility as a function of state $S$ in the internal- and external-habit cases of our model. Several features are worth noting. First, internal-habit marginal utility is always positive. This fact verifies that more consumption is always socially desirable despite the externality. Second, internal-habit and external-habit marginal utility are nearly proportional near the steady state $\bar{S}$, as in the linear example. This feature makes sense since the nonlinear habit accumulation process is approximately linear near the steady state. Third, internal-habit marginal utility falls away from externalhabit marginal utility as the surplus consumption ratio varies far from the steady state. As we move farther from the steady state, changes in consumption have larger impacts on future habits, even immediately (as we saw above, $d x / d c$ rises). The more an increase in consumption raises habits, of course, the less it raises utility.

The fact that this version of internal-habit marginal utility is nearly proportional to external-habit marginal utility is encouraging for the robustness of our model to the habit specification. We repeated all the analysis above and found that many features of the asset pricing predictions are maintained. The average excess return and unconditional Sharpe ratio are not much affected, and price/dividend ratios and expected returns vary with the state variable $S$ about as 
before. However, the small deviations from proportionality of marginal utility turn out to have some significant effects on other predictions. Most important, this internal-habit version of our model generates risk-free rates that are higher and vary with the state variable $S$, so the excess return is a less sensitive function of the state variable and is less predictable.

However, in this comparison we close the internal-habit model as an endowment economy with a random walk in consumption rather than with a constant risk-free rate, we use the same parameter values that were selected to match moments with the external-habit specification, and we use the same habit formation process that was reverse-engineered to deliver a constant risk-free rate with random walk consumption and external habit. The asset pricing results might be closer if one reverse-engineered a different habit accumulation equation to deliver constant risk-free rates and random walk consumption with internal habits; if one closed the existing model using a constant interest rate, tolerating a possibly small predictability of consumption growth; or if one picked parameters to match moments using the internal-habit specification.

The predictions of internal- versus external-habit models for individual behavior can be quite different. One may be forced to the external-habit view when one wishes to integrate the lessons of aggregate and microeconomic data. If an individual with an internal or "addictive" habit and the ability to save receives an idiosyncratic windfall, he will increase consumption slowly and predictably. If an individual with an external habit receives an idiosyncratic windfall, his consumption will rise immediately. (An aggregate windfall can have different effects because it can cause asset prices to move, which is why the distinction between internal and external habits may make little difference to aggregate consumption behavior.) The vast literature on the permanent income hypothesis finds that individual consumption changes are quite difficult to predict. If anything, people spend windfalls even more quickly than predicted by the simple permanent income hypothesis, not too slowly. In analyzing risk aversion, we found that the external-habit model produces just such "overreaction" to individual wealth shocks, $\partial c_{t} / \partial w_{t} \geq 1$, because precautionary saving falls when individual wealth increases.

\section{Conclusion}

We have documented a broad variety of empirical successes for our consumption-based model with external habit formation. We calibrate the model to fit the unconditional equity premium and riskfree interest rate. The model then generates long-horizon predict- 
ability of excess stock and bond returns from the dividend/price ratio and mean reversion in returns; it generates high stock price and return volatility despite smooth and unpredictable dividend streams; and it generates persistent movements in return volatility. All these phenomena are linked to economic fluctuations: When consumption falls, expected returns, return volatility, and the price of risk rise, and price/dividend ratios decline. The model predicts many puzzles that face the standard power utility consumptionbased model, including the equity premium and risk-free rate puzzles and the low unconditional correlation of consumption growth with stock returns. The model is consistent with an even sharper long-run equity premium puzzle that results from mean reversion in stock prices, together with low long-run consumption volatility. When we feed actual consumption data to the model, the model captures the main secular and business cycle swings in stock prices over the last century. The results are almost completely unchanged whether one uses a consumption claim or claims to volatile dividends that are very poorly correlated with consumption. The model predicts all this time variation despite a constant real interest rate and constant conditional moments for consumption and dividend growth.

In order to match these features of the data, our model posits a fundamentally novel view of risk premia in asset markets. Individuals fear stocks primarily because they do badly in recessions (times of low surplus consumption ratios), not because stock returns are correlated with declines in wealth or consumption.

The parameter values in our calibrated model imply that habits are only about 5 percent lower than consumption on average. This degree of habit formation may seem rather extreme. However, in this calibration we have used the sample period and the variable definitions that give the smoothest consumption and highest equity premium, we have ignored sampling variation and survivorship bias in mean returns, and we have not used standard devices to boost the equity premium such as occasional extremely bad states in the consumption distribution or frictions that concentrate stock ownership on a subset of the population. A less ambitious calibration exercise can produce similar dynamic results with a considerably higher average surplus consumption ratio.

The model gives some hope that finance can productively search for fundamental risk factors that explain at least the time-series behavior of aggregate stock returns rather than just relate some asset returns to other asset returns, leaving fundamental issues such as the equity premium as free parameters. The model also suggests that habit formation, or some other device to generate time-varying 
countercyclical risk premia along with relatively constant risk-free rates, is an important element for producing macroeconomic models with realistic production sectors that capture asset price movements as well as quantity dynamics.

\section{References}

Abel, Andrew B. "Asset Prices under Habit Formation and Catching Up with the Joneses." A.E.R. Papers and Proc. 80 (May 1990): 38-42.

"Risk Premia and Term Premia in General Equilibrium." J. Mone" tary Econ. 43 (February 1999): 3-33.

Black, Fischer. "Studies of Stock Price Volatility Changes." In Proceedings of the Business and Economic Statistics Section, American Statistical Association. Washington: American Statis. Assoc., 1976.

Boldrin, Michele; Christiano, Lawrence J.; and Fisher, Jonas D. M. "Asset Pricing Lessons for Modeling Business Cycles." Manuscript. Evanston, Ill.: Northwestern Univ., 1996.

Bollerslev, Tim; Chou, Ray Y.; and Kroner, Kenneth F. “ARCH Modeling in Finance: A Review of the Theory and Empirical Evidence." J. Econometrics 52 (April/May 1992): 5-59.

Campbell, John Y. "Understanding Risk and Return." J.P.E. 104 (April 1996): 298-345.

19sset Prices, Consumption, and the Business Cycle." In Handbook of Macroeconomics, edited by John B. Taylor and Michael Woodford. Amsterdam: North-Holland, 1999.

Campbell, John Y., and Cochrane, John H. "By Force of Habit: A Consumption-Based Explanation of Aggregate Stock Market Behavior." Working Paper no. 4995. Cambridge, Mass.: NBER, January 1995.

. "Appendix to 'By Force of Habit: A Consumption-Based Explanation of Aggregate Stock Market Behavior.' " Manuscript. Cambridge, Mass.: Harvard Univ.; Chicago: Univ. Chicago, 1998. (a)

. "Explaining the Poor Performance of Consumption-Based Asset Pricing Models." Manuscript. Cambridge, Mass.: Harvard Univ.; Chicago: Univ. Chicago, 1998. (b)

Campbell, John Y., and Shiller, Robert J. "The Dividend-Price Ratio and Expectations of Future Dividends and Discount Factors." Rev. Financial Studies 1, no. 3 (1988): 195-227. (a)

- "Stock Prices, Earnings, and Expected Dividends." J. Finance 43 (July 1988): $661-76 .(b)$

Chapman, David A. "Habit Formation and Aggregate Consumption." Econometrica 66 (September 1998): 1223-30.

Chou, Ray Y.; Engle, Robert F.; and Kane, Alex. "Measuring Risk Aversion from Excess Returns on a Stock Index." J. Econometrics 52 (April-May 1992): 201-24.

Cochrane, John H. "Volatility Tests and Efficient Markets: A Review Essay." J. Monetary Econ. 27 (June 1991): 463-85.

. "Explaining the Variance of Price-Dividend Ratios." Rev. Financial Studies 5, no. 2 (1992): 243-80.

Cochrane, John H., and Hansen, Lars Peter. "Asset Pricing Lessons for Macroeconomics." In NBER Macroeconomics Annual, vol. 7, edited by Olivier J. Blanchard and Stanley Fischer. Cambridge, Mass.: MIT Press, 1992. 
Constantinides, George M. "Habit Formation: A Resolution of the Equity Premium Puzzle." J.P.E. 98 (June 1990): 519-43.

Constantinides, George M., and Duffie, Darrell. "Asset Pricing with Heterogeneous Consumers." J.P.E. 104 (April 1996): 219-40.

Cox, John C.; Ingersoll, Jonathan E., Jr.; and Ross, Stephen A. "A Theory of the Term Structure of Interest Rates." Econometrica 53 (March 1985): 385-407.

Deaton, Angus. Understanding Consumption. New York: Oxford Univ. Press, 1992.

Deaton, Angus, and Muellbauer, John. Economics and Consumer Behavior. New York: Cambridge Univ. Press, 1980.

Duesenberry, James S. Income, Saving, and the Theory of Consumer Behavior. Cambridge, Mass.: Harvard Univ. Press, 1949.

Epstein, Larry G., and Zin, Stanley E. "Substitution, Risk Aversion, and the Temporal Behavior of Consumption and Asset Returns: An Empirical Analysis." J.P.E. 99 (April 1991): 263-86.

Fama, Eugene F. "Stock Returns, Expected Returns, and Real Activity." $J$. Finance 45 (September 1990): 1089-1108.

Fama, Eugene F., and French, Kenneth R. "Dividend Yields and Expected Stock Returns." J. Financial Econ. 22 (October 1988): 3-25. (a)

- "Permanent and Temporary Components of Stock Prices." J.P.E. 96 (April 1988): 246-73. (b)

."Business Conditions and Expected Returns on Stocks and Bonds." J. Financial Econ. 25 (November 1989): 23-49.

Ferson, Wayne E., and Constantinides, George M. "Habit Persistence and Durability in Aggregate Consumption: Empirical Tests." J. Financial Econ. 29 (October 1991): 199-240.

Ferson, Wayne E., and Merrick, John J., Jr. "Non-stationarity and Stage-ofthe-Business-Cycle Effects in Consumption-Based Asset Pricing Relations." J. Financial Econ. 18 (March 1987): 127-46.

Hansen, Lars Peter, and Jagannathan, Ravi. "Implications of Security Market Data for Models of Dynamic Economies." J.P.E. 99 (April 1991): 225-62.

Hansen, Lars Peter, and Sargent, Thomas J. "Recursive Models of Dynamic Linear Economies." Manuscript. Chicago: Univ. Chicago, 1998.

Harvey, Campbell R. "Time-Varying Conditional Covariances in Tests of Asset Pricing Models." J. Financial Econ. 24 (October 1989): 289-317.

Heaton, John C. "An Empirical Investigation of Asset Pricing with Temporally Dependent Preference Specifications." Econometrica 63 (May 1995): 681-717.

Jermann, Urban J. "Asset Pricing in Production Economies." J. Monetary Econ. 41 (February 1998): 257-75.

Kandel, Shmuel, and Stambaugh, Robert F. "Expectations and Volatility of Consumption and Asset Returns." Rev. Financial Studies 3, no. 2 (1990): $207-32$.

- "Asset Returns and Intertemporal Preferences." J. Monetary Econ. 27 (February 1991): 39-71.

MaCurdy, Thomas E., and Shoven, John. "Accumulating Pension Wealth with Stocks and Bonds." Working paper. Stanford, Calif.: Stanford Univ., 1992.

Mankiw, N. Gregory. "The Equity Premium and the Concentration of Aggregate Shocks." J. Financial Econ. 17 (September 1986): 211-19.

Mankiw, N. Gregory, and Shapiro, Matthew D. "Risk and Return: Consumption Beta versus Market Beta." Rev. Econ. and Statis. 68 (August 1986): 452-59. 
Mehra, Rajnish, and Prescott, Edward C. "The Equity Premium: A Puzzle." J. Monetary Econ. 15 (March 1985): 145-61.

Nelson, Daniel B. "Conditional Heteroskedasticity in Asset Returns: A New Approach." Econometrica 59 (March 1991): 347-70.

Poterba, James M., and Summers, Lawrence H. "Mean Reversion in Stock Prices: Evidence and Implications." J. Financial Econ. 22 (October 1988): 27-59.

Rietz, Thomas A. "The Equity Risk Premium: A Solution." J. Monetary Econ. 22 (July 1988): 117-31.

Ryder, Harl E., Jr., and Heal, Geoffrey M. "Optimum Growth with Intertemporally Dependent Preferences." Rev. Econ. Studies 40 (January 1973): 1-33.

Schwert, G. William. "Why Does Stock Market Volatility Change over Time?" J. Finance 44 (December 1989): 1115-53.

Shiller, Robert J. "Consumption, Asset Markets and Macroeconomic Fluctuations." Carnegie-Rochester Conf. Ser. Public Policy 17 (Autumn 1982): 203-38.

Market Volatility. Cambridge, Mass.: MIT Press, 1989.

Siegel, Jeremy J. Stocks for the Long Run: A Guide to Selecting Markets for LongTerm Growth. Burr Ridge, Ill.: Irwin, 1994.

Sundaresan, Suresh M. "Intertemporally Dependent Preferences and the Volatility of Consumption and Wealth." Rev. Financial Studies 2, no. 2 (1989): 73-89.

Weil, Philippe. "The Equity Premium Puzzle and the Risk-Free Rate Puzzle." J. Monetary Econ. 24 (November 1989): 401-21. 